NBER WORKING PAPER SERIES

\title{
THE EFFECT OF COURSE SHUTOUTS ON COMMUNITY COLLEGE STUDENTS: EVIDENCE FROM WAITLIST CUTOFFS
}

\author{
Silvia Robles \\ Max Gross \\ Robert W. Fairlie \\ Working Paper 26376 \\ http://www.nber.org/papers/w26376 \\ NATIONAL BUREAU OF ECONOMIC RESEARCH \\ 1050 Massachusetts Avenue \\ Cambridge, MA 02138 \\ October 2019, Revised November 2020
}

We would like to thank Thomas Barrios for his critical work in the early stages of this project. We are also thankful for helpful comments from Joshua Angrist, Charlie Brown, Sue Dynarski, Ed Glaeser, Brian Jacob, Larry Katz, Amanda Pallais, Jeff Smith, Kevin Stange, Lesley Turner, and seminar participants at De Anza Community College, Harvard University, the University of Michigan, the University of California, Sacramento Center, Mathematica, the Association for Education Finance and Policy, and the Association for Public Policy Analysis and Management. We are extremely grateful to Mallory Newell, Andrew LaManque, Bob Barr, Howard Irvin, Stephen Fletcher, Lydia Hearn, Kathleen Moberg, Jerry Rosenberg, and Rowena Tomaneng for providing administrative data and detailed information on courses, minority student programs, and registration procedures. Mallory Newell deserves special thanks for also providing detailed comments on an earlier draft of the paper. This research was funded with help from PR/Award R305B150012\# by the Institute of Education Sciences, U.S. Department of Education. Any opinions, findings, conclusions, or recommendations expressed in this material are those of the authors and do not reflect the views of any other entity, nor of the National Bureau of Economic Research.

NBER working papers are circulated for discussion and comment purposes. They have not been peer-reviewed or been subject to the review by the NBER Board of Directors that accompanies official NBER publications.

(C) 2019 by Silvia Robles, Max Gross, and Robert W. Fairlie. All rights reserved. Short sections of text, not to exceed two paragraphs, may be quoted without explicit permission provided that full credit, including $\odot$ notice, is given to the source. 
The Effect of Course Shutouts on Community College Students: Evidence from Waitlist Cutoffs Silvia Robles, Max Gross, and Robert W. Fairlie

NBER Working Paper No. 26376

October 2019, Revised November 2020

JEL No. I21,I23

\begin{abstract}
One frequently cited yet understudied channel through which funding levels impact college students is course availability-colleges are often forced to respond to budgetary pressure by reducing course offerings. We provide the first causal evidence on this mechanism at a community college, using administrative course registration data and a novel research design that exploits discontinuities in course admissions created by waitlists. Community colleges enroll about half of U.S. undergraduates and over half of minority students in public colleges. The impacts of course availability in this setting may be especially salient relative to four-year colleges due to open admissions policies, binding class size constraints, and a heavy reliance on state funding. Across a range of bandwidths, we find that students stuck on a waitlist and shut out of a course section were 22 to 28 percent more likely to take zero courses that term relative to a baseline of about 10 percent. Shutouts also increased transfer rates to nearby, but potentially lessdesirable two-year colleges. These results offer some evidence that course availability can disrupt community college students' educational trajectories.

Silvia Robles

Mathematica

220 E. Huron St.

Ann Arbor, Mich 48104

robles.silvia@gmail.com

Max Gross

Mathematica

23102 Peachtree Court

Lawrenceville, NJ 08648

mgross@mathematica-mpr.com

Robert W. Fairlie

Department of Economics

Engineering 2 Building

University of California at Santa Cruz

Santa Cruz, CA 95064

and NBER

rfairlie@ucsc.edu
\end{abstract}




\section{Introduction}

State funding for higher education in the United States has dramatically declined over the past decade. Budget cuts following the Great Recession have persisted even 10 years later; funding for public two and four-year colleges in 2017 was $\$ 9$ billion less than its pre-recession level in 2008 (Mitchell, Leachman, and Masterson, 2016). Despite some evidence that funding levels have an impact on college completion rates, the mechanisms through which such resource effects operate are unclear. Anecdotally, overburdened college budgets are often associated with course overcrowding. When a college faces budgetary pressure, it may reduce course offerings or the number of sections per course and students may find themselves unable to enroll in the courses they need to complete a degree. This hypothesis appears in the academic literature as well. For example, Bound and Turner (2007) and Deming and Walters (2017) cite oversubscribed courses as a likely mechanism to explain the relationship between funding and college student outcomes, yet do not test it directly.

Credibly identifying the impact of limited course availability is challenging. Doing so requires detailed course registration data as a means to determine what classes students wish to take. It also requires exogenous variation in who is rationed out of a course. Using newly available data, this paper provides some of the only causal evidence on the impact of being shut out of a college course and the first causal estimates of its impacts among community college students. Community colleges enroll 47 percent of all U.S. undergraduate students in public colleges and 55 percent of underrepresented minority students (Snyder, de Brey, and Dillow, 2018). Their open enrollment policies, binding class size constraints, lower tuition rates, and heavy reliance on state funding may make course scarcity especially salient relative to four-year colleges.

We use novel administrative course registration data from a large community college in California to construct waitlist queues for each course. We link these data to transcript data containing student course schedules, grades and degrees, as well as to the National Student Clearinghouse (NSC), which contains enrollment information at most two and four-year 
college in the United States. The analysis measures the discontinuous impact of being stuck on a waitlist and unable to enroll in one's desired course on a student's current and future course-taking at the community college, as well as transfers to and degree completion at other postsecondary institutions.

Our study is the first to use waitlist queues and admissions cutoffs as discontinuous breaks to determine who is able to or unable to enroll in a course. To understand the intuition behind this design, consider a section for an introductory English composition course. Suppose the section has a waitlist with two people on it and before the end of the registration period, just one formerly enrolled student decides to drop out. This would give the first person on the waitlist the opportunity to enroll in her desired section, but not the second person. The admissions cutoff - the waitlist number below which a student does not get an opportunity to enroll - is very difficult to manipulate, because waitlisted students can not reliably predict how many seats will open up. This introduces exogenous variation in who is able to take their desired courses. Our new approach, leveraging waitlists for causal inference, can be applied broadly in many other contexts.

The analysis primarily takes a local randomization approach to regression discontinuity analysis to compare students who signed up for a course-section waitlist and just missed or made the admissions cutoff. Unlike a continuity-based framework, the local randomization approach explicitly treats observations in a narrow window around the cutoff like a randomized experiment. Cattaneo, Idrobo, and Titiunik (2018) argue that in settings like ours with a very discrete running variable - those with only a few mass points around the cutoff-local randomization is the preferred estimation strategy. We conduct our analysis using bandwidths around the admissions cutoff of one, two, and three spots, where a bandwidth of one includes only the student who just made and the student who just missed the threshold. Balance tests indicate that pre-determined student characteristics are comparable across the cutoff using a bandwidth of one and two, but somewhat less so with larger bandwidths as we move farther from the true natural experiment. 
We find that students who were not able to enroll in their preferred section due to oversubscription were more likely to sit out the term altogether, referred to here as "stop-out." The increase in stop-out rates ranges from 2.3 to 2.8 percentage points depending on the bandwidth. These effects represent a 22 to 28 percent increase relative to the 10 percent stop-out rate among control compliers - those who enrolled in their desired section by the end of the registration period precisely because they got off the waitlist. This finding is statistically significant at the 10 percent level using our most conservative bandwidth, and at the 5 percent and 1 percent levels when using the larger two- and three-spot bandwidths, respectively. Notably, we can rule out even small negative impacts on stop-out with a bandwidth of one, greater than a 0.2 percentage point decrease. Course shutouts may also cause students who do enroll to reduce their course load; students were 1.7 to 5.1 percentage points less likely to enroll in three or more courses. This finding is somewhat less robust, however, and is statistically significant only when using the larger two bandwidths.

Although students were no more or less likely to transfer to another two or four-year school within one year of being stuck on a waitlist, we find that they were 25 to 34 percent more likely to transfer to other two-year schools within two years of missing the waitlist cutoff. This result is statistically significant at the 5 percent level across all three bandwidths and the rise in transfers to other two-year schools does not dissipate three, four, and five years out. In particular, students tended to transfer to nearby two-year schools within a 30 minute driving distance. These nearby schools have lower degree completion rates and their students have lower earnings years later, both of which might indicate a reduction in college quality.

We find no average effect of shutouts on completion rates for associate degrees, certificates, or bachelor's degrees within five years, yet there are divergent impacts by student race and ethnicity. Shutouts caused underrepresented minority students to transfer to another two-year school, whereas Asian students, the largest racial group at the college, responded to rationing by transferring to four-year colleges sooner than they would have otherwise. This 
led to a corresponding increase in bachelor's degree completion rates within five years of the waitlist for Asian students.

The findings from our study contribute to the broader literature on the impacts of resources in higher education. Most of the work in this space uses aggregate data - and in some cases even variation in the incoming class sizes, which could induce course scarcity — as instruments for variation in dollars spent per student (Bound and Turner (2007); Fortin (2006); Deming and Walters (2017). Notwithstanding the work using aggregate data, there is limited causal evidence on micro-level pathways through which college budgets could affect student outcomes. Some studies have implied ways that resources could matter by evaluating resource-intensive interventions such as financial incentives (Barrow et al., 2014), tutoring, mentoring (Bettinger and Baker, 2014), or full-service wrap-around programs such as the CUNY ASAP experiment (Scrivener et al., 2015), and generally have found positive effects.

The findings also contribute to the limited literature on course scarcity. Two recent studies use administrative data from public, four-year universities in California and instrument for course shutouts using variation in the timing when students are first allowed access to the course registration systems. Kurlaender et al. (2014) use random assignment within registration priority blocks to instrument for the average number of shutouts a student experiences over their first four years. Similarly, Neering (2018) uses random assignment to registration priority sequences to instrument for the number of shutouts a student experiences in a given term. Although Neering (2018) finds that shutouts reduce the number of credit units students attempt in that term, neither study detects downstream impacts on bachelor's degree completion or time to degree.

We extend the literature on course scarcity in three ways. First, we offer a new identification strategy that directly compares students just able to get off waitlists and into their desired courses to those who are shut out of the course. Second, this is the first paper to document the impacts of course shutouts in a community college, where there are at least four reasons why course scarcity may be more salient: (1) community colleges have open enrollment 
policies, unlike selective four-year schools that can reject applicants in order to manage course demand; (2) tuition is much lower at community colleges, which reduces the barrier to entry and also fuels demand; (3) community colleges are particularly reliant on funding from state governments, which are affected by budgetary pressures; and (4) section enrollment at many community colleges in California is often capped at 40 to 50 students, whereas class sizes at four-year schools may be allowed to expand more readily. Our third contribution is that the granularity of the registration attempt data allows our analysis to examine heterogeneity by course characteristics like subject and popularity.

This paper also contributes to a small literature on course registration behavior. Registration attempt data have rarely been used for descriptive analysis, let alone causal inference (Gurantz, 2015). Most relevant to our study, Gurantz (2015) finds that community college students often register for classes well after their designated time. Our paper presents an innovative method for circumventing the selection bias in registration time that may prove useful in future work with similar data, especially in settings where registration priority is not randomly assigned. More broadly, understanding the reasons why students delay registration is critical as delays affect the extent to which students experience scarcity.

\section{Institutional Background}

The study uses administrative data from De Anza Community College, a large two year college located in the Bay Area. De Anza is part of the California Community College system, the largest higher education system in the United States (115 colleges across 73 districts). The college has an average total enrollment of approximately 23,000 students per year and costs about $\$ 3,000$ per year for a full-time student. Yearly tuition is higher than the average two-year school in the United States $(\$ 1,269)$, yet is much lower than public four-year colleges $(\$ 9,230)$ (Deming, Goldin, and Katz, 2012, Table 2, page 156). The college operates on a quarter system, yet has substantially lower enrollment during the summer term. ${ }^{1}$ 
De Anza offers a particularly useful setting for examining the impact of course shutouts. For one, community colleges are an important sector of the higher education landscape in California and nationally. In California, nearly half of all students attending a four-year college previously attended a community college. ${ }^{2}$ Furthermore, transfers from California community colleges to the California State University (CSU) system are projected to increase over time (Wilson, Newell, and Fuller, 2010). Thus, two year schools are an increasingly vital step in the accumulation of human capital and production of labor market skills.

Most pertinent to this study, De Anza is a likely setting for observing course scarcity. The data includes the years during the Great Recession, when California community colleges decreased the size of their staff by 8 percent due to budget shortfalls that were harmful for maintaining course offerings (Bohn, Reyes, and Johnson, 2013). Moreover, like all community colleges in California, De Anza has an open enrollment policy; anyone with a high school diploma or equivalent is automatically admitted. Open enrollment can create demand pressures. Although colleges could respond to scarcity in the short run by creating additional sections if they observe excess demand during the registration period, both empirical and anecdotal evidence from De Anza administrators suggest that this was not the case. In the data, we find no course sections where the first student enrolled a few days after a different section of the same course filled up. One reason is that the marginal cost of adding a section is non-trivial. According to De Anza's salary schedule, most instructors are paid between $\$ 7,500$ and $\$ 9,000$ to teach an additional section; however, the actual marginal cost is likely more expensive than that. This figure does not factor in any costs or constraints of classroom space or equipment, any increase in fringe benefit costs, or the difficulty of hiring instructors in a part of the state with consistently lower-than-average unemployment rates and a high cost of living. In addition, some fields, such as math and statistics, face a challenge in finding additional instructors. Furthermore, De Anza cannot simply increase the number of students permitted into a section. Class sizes are commonly capped at 40 or 50 students because of faculty labor union negotiations and available classroom configurations, and larger classes 
often count as double or triple teaching credit for instructors.

\subsection{Data Sources}

This study benefits from access to community college institutional records and data from the National Student Clearinghouse (NSC). Data from the college include registration attempt logs, student demographic characteristics and student-level transcript records, and cover the time period from fall 2002 to spring 2010. Students are linked to their transcripts, which record grades and credits for every course offered by the college during the sample period. In addition, internal data on associate's degrees and certificates are available through summer 2010 .

Especially important for the analysis, detailed logs document each registration attempt during a term's registration period. Each enrollment attempt is identified by a student identifier, time (with precision to the second), and course section. The logs report an outcome for each attempt that can take one of four values: enrolled in the section, placed on a waitlist, dropped from the section, or no change. The difficulty of obtaining data of this nature has prohibited most analyses of course scarcity on a micro level.

Students are also matched to the NSC, which records enrollment at most postsecondary institutions in the United States, through summer 2016. The NSC also provides data on degrees earned from these institutions, supplementing administrative records on degree completion from De Anza. This allows us to examine effects on certificate and associate's degree completion from two-year colleges as well as bachelor's degree completion from four-year schools many years after a students' registration attempt at De Anza.

We examine the impact of course shutouts on a number of student outcomes. First, we focus on course-taking at De Anza in the waitlisted term by examining impacts of enrolling in zero, one or two, and three or more courses. Enrolling in zero courses can be thought of as stop-out, since the student may appear again in a later term. ${ }^{3}$ Enrollment in one or two courses is like enrolling part-time, whereas three or more courses is roughly full-time 
enrollment. We also explore impacts on enrollment at De Anza in the next major term. Second, we study transfers to other two-year schools. Since the data only include enrollment in other two-year schools - and not transcript records from those schools - the analysis cannot disentangle whether students transfer only to take their waitlisted course or for a larger course load. ${ }^{4}$ Third, we analyze transfers to four-year schools. Fourth, we examine certificate and associate's degree completion from either De Anza or other two-year schools. Finally, we study bachelor's degree completion from four-year schools.

\subsection{Section Enrollment}

The online registration process takes place one to two months before the term begins. It is governed by an automated system and students are given one of seven enrollment priority designation dates, upon which they are granted access to the registration system. Registration priority is primarily determined by credit accumulation, although some students are assigned special priority if they are an athlete, a veteran, or are involved with the Extended Opportunities Programs and Services. The registration priority assignment rules should generate discontinuous changes in the time that students sign up for courses, independently of any waitlist effects. Therefore, we conduct all analysis within registration priority and special student categories.

When a given student searches for a desired section (e.g., MWF 9-10AM) of a desired course (e.g., ECON 101 Principles of Microeconomics), she is informed of the location, instructor, and the available number of seats for that particular section. If there are no seats available, the system displays the number of other students on the waitlist. ${ }^{5}$ The data reveal that courses are less likely to become oversubscribed if they meet on weekends, before 9:00AM, or after 5:00PM, though we only observe such scheduling information for course sections after the 2007 summer term in the administrative records.

There are a few rules governing the waitlist process. Students on a waitlist for one section of a course are not allowed to register for the waitlist of other sections of the same course 
and cannot register for sections of other courses that meet at the same time. According to current policies, if a seat opens up in a section during the registration period, waitlisted students are automatically enrolled in the section. Archived records of the waitlist policy are only available going back to 2008, yet anecdotes about the policy before 2008 suggest that when students on the waitlist were notified of an opening, they were given 24 hours to enroll. If they did not enroll in 24 hours, then the next student on the waitlist could claim

the spot. Importantly, the main results are robust when we restrict the analysis to attempts between 2008 to 2010 (Table A8).

The analysis focuses on registration attempts before the term begins. After the term begins, instructors have more discretion over enrollment and often make enrollment conditional on attendance. The first stage estimates the impact of missing a waitlist cutoff on being enrolled in the waitlisted section at the end of the registration period, prior to the start of classes. Many of the outcomes concern enrollment patterns as well. For these, enrollment is defined as being enrolled after the add/drop period a few weeks into the term.

\subsection{Sample Characteristics}

Our analysis sample consists of students who registered for a course waitlist during the registration period between fall 2002 and spring 2010. Community colleges serve a wide variety of people, including students hoping to transfer to four-year schools, those completing a vocational degree, and those taking a recreational course. For ease of interpretation and to make a cleaner comparison to previous studies on course shutouts at four-year schools, we focus our main analysis on students attempting to earn a two-year associate's degree or transfer to a four-year institution, and for whom enrolling in a bachelor's program in a four-year institution could be considered a reasonable substitute. However, the analysis is robust to including all students regardless of their educational goals. ${ }^{6}$ In addition, we exclude registration attempts in the optional summer term from the analysis sample.

We focus on the first waitlist a student ever signed up for in order to avoid dynamic issues 
in the research design. Although students may sign up for waitlists in subsequent terms, the analysis is explicitly testing the hypothesis that missing a waitlist cutoff influences whether a student appears in a subsequent semester. In addition, students may sign up for another waitlist in the same term. To the extent that the first waitlist a student signs up for represents the course that they most desire to enroll in, the analysis can be thought of as the effect of scarcity in the courses students most care about. Ultimately, the results are robust to including all waitlists and clustering standard errors at the student level.

Table 1 reports summary statistics at the section and student levels. Column (1) of Panel A shows that just under half of all sections were ever oversubscribed. This statistic masks differences across subject areas. $68 \%$ of all sections in science, technology, engineering, and math (STEM) courses are oversubscribed during the registration period, compared with 50 percent of arts \& humanities sections, 60 percent of social science courses, and only 30 percent of sections for other courses. For classes that were oversubscribed, the average waitlist had eight students still on it at the end of the registration period. ${ }^{7}$ Column (2) of Panel A shows the subject breakdown for all course sections included in the analysis. By definition, these sections all had waitlists. 34 percent of sections included in the analysis are in STEM fields, 28 percent are in arts and humanities, 12 percent are social science courses, and 26 percent fall into other subject areas.

Panel B shows descriptive statistics for students in the analysis compared to the California average. Column (1) reports demographics for all two-year colleges in California from the Integrated Postsecondary Education Data System (IPEDS). Column (2) contains information for all students who ever enrolled or attempted to enroll for a course at De Anza Community College during the sample period, and Column (3) reports the characteristics for students included in the analysis sample who just made or missed the admissions cutoff. De Anza serves slightly more women than men, though the ratio is not higher than the California average. The ethnic breakdown reflects the demographics of the Bay Area: in Column (2), 40 percent of students are Asian, 26 percent are white, 14 percent are Hispanic, and 
5 percent are Black. Relative to the state average, De Anza students are less likely to be underrepresented minorities and less likely to receive financial aid.

As shown in Column (3), the analysis sample contains registration attempts from 4,258 unique students. These students are more likely to receive financial aid and are younger than the De Anza student population. Students in Column (3) take an average of 1.81 courses in their first observed term relative to the population average of 1.70. Finally, in-sample students appear on 1.01 waitlists during the registration period in their first term,

on average. Among all De Anza students who attempt to register during the advanced registration period, the average number of waitlists in the first observed term is just 0.42 . De Anza students as a whole are thus less likely to sign up for waitlists and take fewer courses. Like the differences in age, this is consistent with the restrictions on students' educational goals, which select students with an intention to transfer to a four-year school or earn a two-year degree.

\section{Empirical Strategy}

The analysis employs a fuzzy regression discontinuity design using waitlist queues to form a running variable. To illustrate the intuition behind the design, suppose a course section has a waitlist with two people on it. By the end of the registration period, if one formerly enrolled student decided to drop out, then the first person on the waitlist would have the opportunity to enroll in her desired section, whereas the second person would not. Although the decision to sign up for a waitlist is clearly endogenous and likely related to the number of students on the waitlist, it is difficult to anticipate how many spots will open for any given section, and, therefore, how deep into the queue admission offers will be extended. This makes the cutoff very difficult - if not impossible - to manipulate. 


\subsection{Construction of the Running Variable}

Conceptually, the running variable represents the number of spots that would have needed to open up in order for a student to have the opportunity to enroll during the registration period, assuming she never dropped out of the queue. Figure 1 shows a hypothetical enrollment $\log$ to illustrate the running variable construction. The first column $P_{i}$ is a student identifier that represents the chronological order in which students initially sign up for any section or section waitlist. A student who enrolls in a section without ever having been on a waitlist also has a position $P_{i}$. However, $X_{i}$, the initial waitlist position, is only defined for students who enter a waitlist queue. In Figure 1, $X_{42}=1$, as student 42 is first on the waitlist when she signs up and similarly, $X_{43}=2$ and $X_{44}=3$.

Importantly, the initial waitlist position is not the same as the running variable. Rather, the running variable for student $i$ also involves $D_{i}$, the number of students who registered before student $i$ and dropped out during the registration period after student $i$ registered. In Figure 1, both student 7 and student 22 enrolled before students 42, 43, and 44, and dropped out after these students entered the waitlist. Therefore, $D_{42}, D_{43}$ and $D_{44}$ all equal two. Although student 38 also dropped out of the queue, this occurred before students 42 , 43 , and 44 signed up for the waitlist and therefore student 38 has no effect on $D_{42}, D_{43}$ or $D_{44}$. Essentially, $D_{i}$ counts the types of drops that would move a student up on the waitlist or create a spot for her in the section.

The running variable $R V_{i}$ is defined as the difference between a student's initial waitlist position and the number of drops $D_{i}$,

$$
R V_{i}=X_{i}-D_{i} .
$$

Students with a strictly positive running variable would not have had the opportunity to enroll in the section during the registration period. Students with running variables less than or equal to zero would have had an opportunity to enroll, conditional on staying in 
the queue. A student can only influence her own running variable by signing up, not by dropping out. For example, although student 44 eventually dropped off of the waitlist, she still received a running variable. This paper compares the outcomes of students who just made the waitlist cutoff $\left(R V_{i} \leq 0\right)$ to those who just missed it $\left(R V_{i}>1\right) .{ }^{8}$

This running variable construction is preferred to other possible definitions because it preserves the order in which students sign up for the waitlist. For example, suppose student A signs up to a waitlist that already has two people on it and student B signs up the next day - but in the interim two people have dropped out of the class. Student B would be in the second position, but student B's running variable, as defined above, could not be smaller than student A's. A running variable based on the time that students sign up would also have this order-preserving feature; however, the construction of a cutoff time is not obvious. ${ }^{9}$

Of course, students continue to enroll and drop after the registration period ends. The analysis does not include these attempts because there is a larger role for instructor discretion once the quarter begins. There is imperfect compliance since students can drop out of the queue. That is, students with $R V \leq 0$ might not actually be enrolled in the section at the end of the registration period. ${ }^{10}$ Thus, estimates use a fuzzy RD design as opposed to a sharp RD.

\subsection{Estimation}

Consider a student who placed herself on a waitlist. Let $Y_{i}(1)$ be her educational outcome if she does not enroll in her preferred section during the registration period and $Y_{i}(0)$ be her educational outcome if she does. The analysis estimates $\mathbb{E}\left[Y_{i}(1)-Y_{i}(0) \mid R V_{i s t}>0\right]$. This is interpreted as the local average treatment effect (LATE) for compliers-students who are rationed out of a section if they miss the cutoff and are induced to enroll if they make the cutoff. It is important to consider the type of student represented by a complier in this scenario. Students discouraged by a waitlist cutoff could be less motivated, less organized, or less savvy navigators of the registration process for reasons that reflect social inequality. 
To estimate the LATE, we use a two-stage least squares regression for students within a small window around the waitlist cutoff. That is, for student $i$ in section $s$ and term $t$ with $R V_{i s t} \in[0,1]:$

$$
\begin{aligned}
& D_{i s t}=\alpha_{0}+\alpha_{1} Z_{i s t}+\mathbf{X}_{\mathbf{i s t}}{ }^{\prime} \Gamma+\delta_{t}+\zeta_{i s t} \\
& Y_{i s t}=\beta_{0}+\beta_{1} \hat{D}_{i s t}+\mathbf{X}_{\text {ist }}{ }^{\prime} \Pi+\delta_{t}+\epsilon_{i s t}
\end{aligned}
$$

where $\hat{D_{i s t}}$ represents the student's predicted probability of not enrolling in the section according to equation 2. Enrollment for the first-stage equation is measured on the last day of the advanced registration period, prior to the start of classes. $R V_{i s t}$ is the running variable and $Z_{i s t}$ is an indicator equal to one if $R V_{i s t}>0$ and equal to zero otherwise. $\mathbf{X}_{\text {ist }}$ is a vector of covariates including gender, race, ethnicity, US citizenship status, age, financial aid receipt, registration priority fixed effects, special admit status, special program status, as well as indicators for missing variables. The $\delta_{t}$ represent a vector of term by year fixed effects, and $\zeta_{i s t}$ and $\epsilon_{i s t}$ are error terms. ${ }^{11}$

The estimates rely on local randomization assumptions to identify the causal effect of not enrolling in a desired section due to oversubscription for compliers (for a detailed description of local randomization see Cattaneo, Titiunik, and Vasquez-Bare, 2017; Cattaneo, Idrobo, and Titiunik, 2018). Essentially, local randomization assumes that within a small bandwidth on either side of the waitlist cutoff, the running variable is unrelated to potential outcomes. That is, assignment of the running variable is "as-if random" and there is no selection into treatment.

Local randomization is appropriate for settings with extremely discrete running variables, as opposed to the more commonly used RD assumptions involving continuity of the regression function, which require a continuous running variable. In fact, Cattaneo, Idrobo, and Titiunik (2018) argue that in settings with a very discrete running variable, local randomization is "possibly the only valid method for estimation and inference." The full set of assumptions 
include the following:

1. Fixed potential outcomes. Potential outcomes are non-random and fixed for students within a small window around the cutoff.

2. Known randomization mechanism. The distribution of the treatment assignment vector is known for those within a small window around the cutoff.

3. Unconfoundedness. Within a small window around the cutoff, whether students end up on the right or left of the cutoff does not depend on potential outcomes.

4. Exclusion restriction. Within a small window around the cutoff, the running variable influences outcomes only through treatment, not directly.

5. Stable unit treatment value assumption (SUTVA). Locally, within a small window around the cutoff, each student's potential outcomes only depend on that student's own treatment assignment and not anybody else's.

6. Monotonicity. Within a small window around the cutoff, missing the cutoff does not cause any students to be more likely to enroll than they otherwise would have been, and making the cutoff does not cause any students to be less likely to enroll.

Assumptions one and two define what is meant by random. ${ }^{12}$ Assumption three is the key to local randomization and has some testable implications; any manipulation of a student's own running variable would violate this assumption. However, a student's running variable is dependent on the number of other students who drop the section, and is thus out of the student's control. ${ }^{13}$ An example of a violation of the assumption is if a student is more likely to sign up for the waitlist because she knows that a friend is planning to drop. This seems unlikely, particularly for our sample which is mostly incoming students who may not know many people. Section 3.3, below, describes our formal tests for manipulation around the cutoff.

Assumption four, the exclusion restriction, is generally not needed in RD studies that rely on continuity of the conditional regression function; indeed, it would be unreasonable to assume that there is no direct relationship between the running variable and the potential outcomes for all values of the running variable. Clearly, somebody who signs up for a section very early in the registration period is different from somebody who signs up very late. 
However, it is more plausible that there is no difference, on average, between people within a small bandwidth around the cutoff.

SUTVA is standard in estimating the LATE using an instrumental variable, though of course it is possible that there are spillovers from other students. Again, one mitigating factor for these possible spillovers is that most students are first-time enrollees and likely do not know each other well. The monotonicity assumption is also standard. Since signing up for a waitlist has a cost - students are barred from signing up for any other section at the same time or for the same course - it is implausible that being high enough on the waitlist to gain admission would cause a student to be less likely to sign up for a course than they otherwise would have been. Being more likely to sign up for a course because one missed the waitlist cutoff is also intuitively unlikely, though not testable.

Equations (2) and (3) are estimated using a two-stage least squares regression. Although Lee and Card (2008) suggest clustering standard errors by the value of the running variable when the running variable is discrete, Kolesar and Rothe (2016) point out that confidence intervals constructed in this way have poor coverage when the number of clusters is small, which is the case in this analysis. Therefore, only the usual heteroskedasticity robust standard errors are used, unless otherwise noted. ${ }^{14}$

\subsection{Validity Checks}

One can test for manipulation of the running variable by checking for smoothness in the density of the running variable at the cutoff. Figure 2 shows the density of the running variable and Table 2 reports p-values from formal tests for smoothness using a McCrary-like test specifically designed for discrete running variables, introduced in Frandsen (2017). The density test fails to reject the null of no manipulation at the 5 percent level across many values of a researcher-chosen parameter representing the maximum amount of nonlinearity in the probability mass function that would still be compatible with no manipulation. ${ }^{15}$

Another testable implication of the assumptions is that predetermined characteristics 
should be balanced across the waitlist cutoff. Table 3 reports the results of linear regressions testing for imbalance in baseline student characteristics across the waitlist cutoff. The regressions condition on term by year fixed effects, registration priority fixed effects, and special student categories that affect registration priority. Using our most conservative bandwidth of one, we find that none of the student characteristics are statistically significant at the 5 percent level. The covariates also are not jointly significant, with a joint F-test yielding a p-value of 0.242 . When we move further from the cutoff using a bandwidth of two, we find no evidence of differences in student characteristics at the 5 percent level except for an indicator of first-time student status. ${ }^{16}$ However, the magnitude of the coefficient on first-time students is substantively small, just one-half of a percentage point on a base of 98 percent, and we control for first-time student status in all of our analyses. As expected, the differences in student characteristics become more pronounced when we move further from the true natural experiment and use an even larger bandwidth of three. Yet even when using a bandwidth of three, the differences that are statistically significant across the cutoff are quite small. ${ }^{17}$ Though we control for all of these observable differences in our analysis, estimates from this larger bandwidth should be interpreted with more caution.

We also examine two other student characteristics that should be very similar across the threshold if there is no selection into treatment. First, students across the cutoff sign up for a similar number of other waitlists during the registration period-1.07 on average for those with a running variable of zero and 1.09 for those with a running variable of one. Since this behavior occurs after students sign up to the initial waitlist, students have some information about their likely schedule, even if it is not full information. Therefore, although this variable cannot be tested formally for balance, the similarity in waitlist enrollment behavior is consistent with "as-if" random assignment. In addition, there is less than a day between the registration attempts of students in the same section with running variable 0 or 1. Specifically, the average amount of time between registration for these students is 19 hours, just 13 percent of a standard deviation between any two registration attempts in a 
waitlisted section.

\section{Course Scarcity and Student Outcomes}

\subsection{First Stage Estimates}

The first stage estimates can be easily seen in discontinuities at the cutoff. Figure 3a shows a discontinuity at the waitlist cutoff for enrollment in the waitlisted section at the end of the registration period. Sixty-four percent of students just to the left of the cutoff-the last to have the opportunity to enroll in the section during the registration period - ended up enrolled in the section. In accordance with the definition of the running variable, students who miss the waitlist cutoff are not able to enroll during the registration period. ${ }^{18}$ The enrollment rates are similar for courses in which a student has been waitlisted for one section (Figure 3b).

Table 4 reports regression-adjusted estimates of the first stage using bandwidths of one, two, and three. Similar to the discontinuity depicted in Figure 3, students who miss the waitlist are about 64 percent less likely to enroll in the desired section (Panel A) and course (Panel B). The F-statistics are all greater than 3500, indicating that there is not a weak instruments problem.

Although estimates of the first stage for section and course enrollment are qualitatively similar, all further analysis uses section enrollment as the endogenous variable of interest, as it is most directly influenced by the waitlist cutoff. However, the results are nearly identical when we define treatment at the course level (Table A8).

\subsection{Causal Effects of Course Scarcity}

Table 5 presents estimates of the LATE of being shut out of a course on enrollment

patterns in the concurrent semester. ${ }^{19}$ Columns (1), (2), and (3) report the effect of being shut out on whether a student enrolls in zero, one to two, or three or more courses 
respectively, and Panels $\mathrm{A}, \mathrm{B}$, and $\mathrm{C}$ show how the results change across a bandwidth of one, two, and three. Overall, we find that students are 2.3 to 2.8 percentage points more likely to "stop-out" in the waitlisted term; that is, to take no course at all that term. This represents a 22 to 28 percent increase in stop-out relative to the stop-out rate of the control compliers, which is 10 percent. This finding is statistically significant at the 10 percent level at the most conservative bandwidth of one; it is statistically significant at the 5 percent level when using the larger two bandwidths. Notably, with the most conservative bandwidth, we can rule out even small negative impacts on stop-out greater than a 0.2 percentage point decrease.

Course shutouts may also cause students who do enroll to reduce their course load. We find that students are 1.7 to 5.1 percentage points less likely to enroll in three or more courses, relative to a control complier mean of about 56 percent. The point estimates are consistently negative across all three bandwidths, and statistically significant for bandwidths of two and three, but not for the bandwidth of one. We do not find a statistically significant impact on the likelihood of enrolling in one or two courses. ${ }^{20}$ In addition, the point estimates suggest that students who were shut out of a course are two to three percentage points less likely to take a course at De Anza in the next term, but this is only statistically significant for a bandwidth of three.

Table 6 shows the effect of course shutouts on transfer rates to other two and four-year colleges. Across all three bandwidths, we find that students are no more or less likely to transfer to another school within one year of being stuck on a waitlist. Taken together with the increase in stop-out at De Anza, this suggests that course shutouts increase the likelihood of dropout from college altogether in the short-run. This dropout effect does not persist, however.

We find a substantively large, positive increase in the transfer rate to other two-year colleges in later years. Students who were shut out are 2.9 to 3.6 percentage points more likely to transfer to another two-year college within two years of missing the waitlist cutoff, 
an increase of 25 to 34 percent. This rise does not dissipate over time. The point estimates for transfers to other two-year schools within three, four, and five years are very similar in magnitude across all specifications, ranging from 2.6 to 3.2 percentage points, and are statistically significant in all but the most conservative bandwidth.

The three most frequent recipients of De Anza's transfer students to other two-year schools are Foothill College, Evergreen Valley College, and San Jose City College, all of which are within a 30-minute drive of De Anza. As shown in Table A2, when estimating the treatment effect on attending each of these alternative schools, there is a statistically significant increase in enrollment at Evergreen, San Jose City College, and all other two-year schools, but not at Foothill. Although there are separate applications, registration priorities, different course requirements (e.g., number of calculus courses), and other differences, De Anza and Foothill are in the same two-college district and relatively close to each other. ${ }^{21}$ According to the U.S. Department of Education's College Scorecard website, De Anza Community College has a higher graduation rate and a lower withdrawal rate, and students who attend De Anza go on to earn higher average salaries than attendees at Evergreen and San Jose City. In addition, online ranking services such as NICHE and Wallethub consistently rank De Anza above those two schools; students might be worse off by enrolling at these common alternatives. Of course, rankings often do not adjust adequately for differences in student-level inputs across colleges (Kurlaender, Carrell, and Jackson, 2016). Even so, revealed preferences indicate that students desire to enroll at De Anza and transfer only because of course oversubscription, which also suggests that these students may be worse off by transferring.

We find no overall impacts on transfers to four-year schools or, as reported in Table 7 , on the share who earn associate's degrees or certificates from De Anza or any other two-year school, or bachelor's degrees up to five years out. 


\subsection{Subgroup Analysis}

This section reports results by subgroup categories, including differential impacts by gender, race/ethnicity, popularity of the course, and course subject. We partition students into three race/ethnicity groups: Asian, white, and underrepresented minority (URM). The URM category consists of Black, Latinx, Native American, multi-racial students, and students who do not fit into any other category. Course popularity and subject are meant to test the idea that not all courses are equally important to a student's educational and labor market goals. ${ }^{22}$

Tables A3 to A6 show the differential effects on course enrollment in the concurrent term for all subgroups using a bandwidth of one. There are no detectable differential impacts on enrollment patterns by demographic subgroups, either gender or race/ethnicity. We also find little evidence for differences by course popularity or subject matter, such as STEM, arts and humanities, social studies, and other subjects.

Interesting dynamics emerge in transfers and degree completion by race and ethnicity categories. ${ }^{23}$ Table 8 reports the effects on transfers to other two-year colleges, transfers to four-year colleges, and bachelor's degree completion separately for Asian, white, and URM students. We show results within three through five years of the waitlist term, which is consistent with how the state office measures these outcomes.

We find large, positive and statistically significant impacts of missing the waitlist cutoff on transfer to other two-years schools for URM students. Meanwhile, other students do not transfer to two-year schools at an appreciably high rate, including near zero point estimates for Asian students and negative point estimates for white students. In contrast, Asian students are more likely to transfer to a four-year school in response to being rationed out of a course. With Asian students accelerating their transfer to four-year schools, we also find a corresponding uptick in bachelor's degree completion for Asian students. There is no impact on bachelor's degree completion for URM students, although the control complier mean for this group is about half that of white and Asian students in the fifth year out. Finally, there 
is evidence that bachelor's degree attainment among white students is hampered by course rationing.

These findings suggest that there could be two streams of students using community college in California as a vehicle to access four-year schools, and the streams might correlate with race and ethnicity. The first group of students use the community college to build skills in a stepping-stone fashion. The second group might be able to gain acceptance to a four-year school initially, but instead strategically choose to start in a two-year setting. This could be because they can complete core courses at a lower tuition rate or because it is relatively easier to gain entry to a four-year public college or university in California as a transfer student. ${ }^{24}$ These results highlight varied potential responses to course scarcity in a community college setting.

\subsection{Sensitivity Analysis}

In addition to robustness across bandwidths one, two, and three already shown in the main analysis, the results of this paper are robust to several other design decisions. First, as is standard in a RD analysis, we check whether there are treatment effects at placebo thresholds. Figure 4 plots the reduced form coefficients for the two main outcomes affected by course shutouts, estimated for 10 different waitlist thresholds and using a bandwidth of one. ${ }^{25,26}$ The two outcomes are: (1) took zero courses in the waitlisted term and (2) transferred to another two-year school within two years. The true cutoff represents the last student on the waitlist who received an offer of admission to the section. For each placebo cutoff $j$, students with $R V_{i s t}=j$ behave as the control group and are compared to students directly to the right, with $R V_{i s t}=j+1$. We find that the differences in outcomes at cutoffs $j \neq 0$ are not significantly different from zero and none are statistically significant at even the 10 percent level.

Table A8 shows that the LATE is robust to different samples of students and alternative specifications. Column (1) includes all students, regardless of which initial educational 
goal they declared, and all waitlists. This examines whether estimates are sensitive to conditioning on students' initial declared intentions listed in Table A1 or to using the students' first waitlist. Column (2) restricts the sample to students who declared an intention to transfer to a four-year school. Column (3) includes only terms after 2007, when documentation

on enrollment rules is available (see Section 2.2 for a discussion of the issue). Column (4) uses the waitlist cutoff to instrument for course enrollment, rather than course section enrollment. Column (5) uses the main analysis sample but adds section by term by year fixed effects to equations 2 and 3. Column (6) also uses the main sample but further restricts it to be unique at the course section by running variable level, by keeping the earliest student to register for the waitlist at each value of the running variable. Finally, Column (7) uses the main sample but applies a continuous regression discontinuity framework by fitting a line on either side of the cutoff, within a bandwidth of 10 . Overall, the estimates in Table A8 consistently show that course shutouts increase stop-out, with magnitudes ranging from 1.2 to 6.3 percentage points. All of these estimates are statistically significant at the 10 percent level and all but one at the 5 percent level. As in the main analysis, the impact on the share of students who take three or more courses is consistently negative in sign, though only some are precisely estimated.

\section{Conclusion}

This paper studies the effect of course scarcity at a large community college by using cutoffs in waitlist queues that discontinuously change the probability of enrolling in a desired section. We introduce a new method for leveraging waitlist registration logs, a data resource that has been previously underused to perform causal inference. Comparing students who just miss the waitlist cutoff to those who just make it, the study finds that students who are not able to enroll in their preferred section due to oversubscription are 2.3 to 2.8 percentage points (22 to 28 percent) less likely to take any courses that term. At the same time, missing 
a waitlist cutoff causes a corresponding 2.9 to 3.6 percentage point (25 to 34 percent) increase in the share of students who transfer to other two-year schools within two years, in some cases enrolling in both schools simultaneously.

Although we find no average impacts of course rationing on transfers to four-year schools or bachelor's degree attainment, there is evidence of differing impacts by student race and ethnicity. For Asian students, facing rationing leads to an accelerated rate of transfer to a four-year college and receipt of bachelor's degrees. Underrepresented minority students are more likely to transfer and continue in other two-year schools. White students seem to delay their transfer to a four-year college and subsequently see a reduction in bachelor's degree receipt.

The results of our study contrast somewhat with earlier work that suggests course scarcity in college does not have downstream effects on student outcomes (Kurlaender et al., 2014; Neering, 2018). One likely reason for this contrast is that there are important institutional differences between community colleges and public four-year universities - the setting studied in earlier work - that amplify the impacts of course scarcity.

Underfunded community colleges are not unique to California; 46 states spent less per-student in 2016 than they did before the 2008 recession (Mitchell, Leachman, and Masterson, 2016). In light of sustained decreases in per-student funding for public colleges, future work should continue to explore the effects of course scarcity at the institution level. In addition, we estimate the effect of missing a single waitlist cutoff holding availability in all other sections fixed. The response to a scenario in which a large fraction of sections are eliminated at once may be very different and presumably more severe. Likewise, students often face more than one waitlist during their college careers. For example, 81 percent of students in our sample signed up for more than one waitlist. In this sense, we present a lower bound on the cumulative impact of missing multiple waitlists.

This paper provides evidence of the impact of course shutouts on educational attainment, a mechanism that was previously untestable due to data limitations. Possible solutions to 
reduce these frictions may include better eliciting student preferences for courses, using data-driven methods to predict course demand, increasing faculty recruiting efforts for high-demand courses, and/or charging higher tuition or fees for more in-demand, high-cost courses. This study continues the work of estimating the effects of higher education funding and specifically funding for community colleges, which disproportionately serve low-income students and students of color. In the face of unequal access to educational resources, it is extremely important for future research to understand the exact processes through which money influences student outcomes, in order to create effective solutions. 


\section{Notes}

${ }^{1}$ See Fairlie, Hoffmann, and Oreopoulos (2014) for more details about De Anza Community College.

${ }^{2}$ See U.S. Department of Education (2017); CCCCO (2012); and Sengupta and Jepsen (2006).

${ }^{3}$ In fact, 84 percent of students who enroll in zero courses in the waitlisted term take at least one course at De Anza in a subsequent term.

${ }^{4}$ We find that roughly 63 percent of these transfers never come back to De Anza to enroll in any future classes. Among the remaining 37 percent of transfers, most only come back to partially enroll at De Anza and continue to take courses at the two-year college to which they transferred.

${ }^{5}$ Courses with at least one oversubscribed section during the registration period have an average of 3.4 total sections. Overall, 73 percent of sections for these courses become oversubscribed during the registration period.

${ }^{6}$ Upon enrolling, students are asked to declare their educational goal or intention. Table A1 lists the categories students can choose from in declaring their intention. The sample includes all students who declare an intention to transfer to a four-year school, earn an associate's degree, or who are undecided.

${ }^{7}$ For reference, the average waitlist had about 14 students ever sign up for it during the registration period. This ranged from an average of 11.5 for waitlists in the arts \& humanities to 16.5 for waitlists in the social sciences.

${ }^{8}$ Student registration behavior is complex and in practice there can be multiple students in a section with the same running variable. On average, course sections included about 1.1 waitlisted students for each value of the running variable within a bandwidth of 10. Our results are robust to a sample where values of the running variable are unique within sections, keeping the first student with each value of the running variable in a given section (Table A8).

${ }^{9}$ In fact, the construction of a cutoff time fully depends on the construction of the current running variable. That is, without a cutoff waitlist position, there can be no cutoff time. Appendix B tests the robustness of the results to a time-based running variable; the findings remain similar.

${ }^{10}$ By definition, students with $R V>0$ could not have enrolled during the registration period, meaning we observe only one-sided noncompliance.

${ }^{11}$ The results are robust to a specification that includes course section by term by year fixed effects (Table A8).

${ }^{12}$ Assumption one means that a student's potential outcomes are fixed and inherent to that student. There is a formulation of the local randomization assumptions for potential outcomes that are random variables as well, but it would not change anything in the mechanics of estimating the LATE parameter (Cattaneo, 
Titiunik, and Vasquez-Bare, 2017).

${ }^{13}$ In some sections, no students drop. In others, as many as 20 students drop. Among sections in the analysis, the 10th percentile number of drops is zero and the 90 th percentile is five.

${ }^{14}$ Treatment assignment is independent within a small window around the cutoff, so we do not cluster by course. However, the results are nearly identical with this alternative clustering scheme and are available upon request.

${ }^{15}$ Frandsen (2017) offers a benchmark for choosing this parameter. If there are about 20 support points within one standard deviation of the cutoff, then the rule of thumb maximum is 0.005 , whereas if there are only 6 support points, it is 0.047 . There are 8 support points in our context, indicating that the density test fails to reject the null at the 10 percent level at values much smaller than the benchmark.

${ }^{16}$ Though the F-test indicates that the characteristics were jointly significant overall, we find that this is entirely driven by first-time students. That is, removing the first-time indicator yields a joint test p-value of 0.18 .

${ }^{17}$ The estimates imply that students who missed the waitlist cutoff were just 1.3 percentage points more likely to be missing race information, 2.4 percentage less likely to be female, one-third of a year older, and 0.4 percentage points more likely to be first-time students.

${ }^{18}$ Thirty percent of students who were stuck on the waitlist at the end of the registration period do eventually enroll in the section. This statistic rises to 42 percent for students with a running variable equal to one.

${ }^{19}$ Figures A1 through A3 visually depict the reduced form effects, plotting the residuals of the main outcome variables, conditioned on baseline characteristics, and binned by values of the running variable.

${ }^{20}$ We cannot distinguish between a cascading effect (i.e., somebody who would otherwise have taken three courses dropping down to two and somebody who would have taken two, dropping down to one, and so on) and a more dramatic shift from a plan to take a full course load to taking no courses, or some combination of these two options.

${ }^{21}$ We find, however, that only 0.9 percent of our sample took a class at Foothill during the same term, and furthermore, that only 1.3 percent took a course at another community college during the same term.

${ }^{22}$ To gauge the popularity of the course, we tallied enrollment requests for all courses across the sample period and picked the top five most requested with the rationale that more popular courses are likely to be important pre-requisites for common majors or for transfer. The top five include three introductory writing courses, a government course, and a psychology course. Indeed, course catalogs confirm that these five classes are all prerequisites for a variety of other courses at the college. Furthermore, they are part of the Intersegmental General Education Transfer Curriculum (IGETC), which allows them to be easily transferred 
toward a bachelor's degree in the UC system and CSU system.

${ }^{23}$ We do not detect impacts on transfer and degree completion for other subgroups. Moreover, the transfer and degree completion results by ethnicity categories are robust to alternative sample definitions.

${ }^{24}$ For example, Berkeley and UCLA acceptance rates are almost twice as high for transfer students than for freshman admits. Anecdotally, these statistics seem well known on college discussion forums.

${ }^{25}$ We perform this placebo threshold exercise using the reduced form rather than the two-stage least squares estimates because the first stage is zero at placebo cutoffs by construction. That is, students to the right of the true cutoff, where the running variable is equal to zero, were not able to enroll in the waitlisted section at the end of the registration period.

${ }^{26}$ Table A7 reports the corresponding point estimates and standard errors represented in the figure. 


\section{References}

Barrow, Lisa, Lashawn Richburg-Hayes, Cecilia Elena Rouse, and Thomas Brock. 2014. "Paying for performance: the education impacts of a community college scholarship program for low-income adults." Journal of Labor Economics 32 (3):563-599.

Bettinger, Eric P. and Rachel B. Baker. 2014. "The Effects of Student Coaching: An Evaluation of a Randomized Experiment in Student Advising." Educational Evaluation and Policy Analysis 36 (1):3-19.

Bohn, Sarah, Belinda Reyes, and Hans Johnson. 2013. "The Impact of Budget Cuts on California's Community Colleges." Tech. rep., Public Policy Institute of California.

Bound, John and Sarah Turner. 2007. "Cohort Crowding: How Resources Affect Collegiate Attainment." Journal of Public Economics 91:877-899.

Cattaneo, Matias, Michael Jansson, and Xinwei Ma. 2017. "Simple Local Regression Distribution Estimators." Working Paper .

Cattaneo, Matias, Rocio Titiunik, and Gonzalo Vasquez-Bare. 2017. "Comparing Inference Approaches for RD Designs: A Reexamination of the Effect of Head Start on Child Mortality." Journal of Policy Analysis and Management 36:643-681.

Cattaneo, Mattias, Nicolas Idrobo, and Rocio Titiunik. 2018. "A Practical Introduction to Regression Discontinuity Designs: Volume I and II." In Cambridge Elements: Quantitative and Computational Methods for Social Science, edited by R. Michael Alvarez and Nathaniel Beck. Cambridge: Cambridge University Press.

CCCCO. 2012. "Focus On Results- Accountability Reporting for the California Community Colleges." Tech. rep., California Community Colleges Chancellor's Office. A Report to the Legislature, Pursuant to AB 1417 (Pacheco, Stat. 2004, Ch. 581).

Deming, David, Claudia Goldin, and Lawrence Katz. 2012. "The For-Profit Postsecondary School Sector: Nimble Critters or Agile Predators?" Journal of Economic Perspectives 26:139-164.

Deming, David J. and Christopher R. Walters. 2017. "The Impact of State Budget Cuts on U.S. Postsecondary Attainment." Working Paper 23736, National Bureau of Economic Research.

Fairlie, Robert W., Florian Hoffmann, and Phillip Oreopoulos. 2014. "A Community College Instructor like Me: Race and Ethnicity Interactions in the Classroom." American Economic Review 104:2567-2591.

Fortin, Nicole. 2006. "Higher Education Policies and the College Premium: Cross-State Evidence from the 1990s." American Economic Review 96:959-987.

Frandsen, Brigham R. 2017. "Party Bias in Union Representation Elections: Testing for Manipulation in the Regression Discontinuity when the Running Variable is Discrete." In Regression Discontinuity Designs, Advances in Econometrics, vol. 38. 281-315. 
Gurantz, Oded. 2015. "Who Loses Out? Registration Order, Course Availability, and Student Behaviors in Community College." Journal of Higher Education 86 (4):524-563.

Kolesar, Michal and Christoph Rothe. 2016. "Inference in Regression Discontinuity Designs with a Discrete Running Variable." Working Paper .

Kurlaender, Michal, Scott Carrell, and Jacob Jackson. 2016. "The promises and pitfalls of measuring community college quality." The Russell Sage Foundation Journal of the Social Sciences 2.1:174-190.

Kurlaender, Michal, Jacob Jackson, Jessical S. Howell, and Eric Grodsky. 2014. "College course scarcity and time to degree." Economics of Education Review 41:24-39.

Lee, David S. and David Card. 2008. "Regression discontinuity inference with specification error." Journal of Econometrics 142:655-674.

McCrary, Justin. 2008. "Manipulation of the Running Variable in the Regression Discontinuity Design: A Density Test." Journal of Econometrics 142 (698-714).

Mitchell, Michael, Michael Leachman, and Kathleen Masterson. 2016. "Funding Down, Tuition Up: State Cuts to Higher Education Threaten Quality and Affordability at Public Colleges." Tech. rep., Center on Budget and Policy Priorities.

Neering, Kyle F. 2018. "Course Closed: The Short- and Long-Run Impacts of Course Shutouts on University Students." Working Paper.

Scrivener, Susan, Michael J. Weiss, Alyssa Ratledge, Timothy Rudd, Colleen Sommo, and Hannah Fresques. 2015. "Double Graduation Rates: Three-Year Effects of CUNY's Accelerated Study in Associate Programs (ASAP) for Developmental Education Students." Tech. rep., MDRC.

Sengupta, Ria and Christopher Jepsen. 2006. "California's Community College Students." California Counts: Population Trends and Profiles 2, Public Policy Institute of California.

Snyder, Thomas D, Cristobal de Brey, and Sally A Dillow. 2018. "Digest of Education Statistics 2016." Tech. rep., National Center for Education Statistics, Institute of Education Sciences, U.S. Department of Education.

U.S. Department of Education. 2017. "Digest of Education Statistics." Tech. rep., Institute of Education Sciences, National Center for Education Statistics, Washington, DC.

Wilson, Stacy, Mallory Newell, and Ryan Fuller. 2010. "Ready or Not, Here They Come The Complete Series of Undergraduate Enrollment Demand and Capacity Projections, 2009-2019." Tech. Rep. 10-08, California Postsecondary Education Commission. 
Table 1: Summary Statistics

Panel A: Section-level statistics

All Sections with

Sections Waitlist

$(1)$

\begin{tabular}{lccc}
\hline \% with a Waitlist (WL) & 0.49 & 1.00 & \\
\% STEM with WL & 0.68 & 0.34 & \\
\% Arts/Humanities with WL & 0.50 & 0.28 & \\
\% Social Sciences with WL & 0.60 & 0.12 & \\
\% Other with WL & 0.30 & 0.26 & \\
WL Length (Mean) & & 8.01 & \\
WL Length (Standard Deviation) & & 7.07 & \\
& & & \\
Observations & 29,614 & 3,499 & \\
Panel B: Student-level statistics & & & \\
& CA Two-Year & All & Analysis \\
& Public Colleges & De Anza & Sample \\
& $(1)$ & $(2)$ & $(3)$ \\
\hline Female & 0.53 & 0.52 & 0.51 \\
Asian & 0.13 & 0.40 & 0.44 \\
White & 0.27 & 0.26 & 0.24 \\
Hispanic & 0.45 & 0.14 & 0.16 \\
Black & 0.07 & 0.05 & 0.05 \\
Ever Receives Aid & 0.59 & 0.17 & 0.32 \\
Age Under 25 & 0.63 & 0.59 & 0.80 \\
Age 25 and Over & 0.37 & 0.41 & 0.20 \\
\# Courses, first term & & 1.70 & 1.81 \\
\# Waitlists, first term & & 0.42 & 1.01 \\
& $1,234,509$ & 179,596 & 4,258 \\
Observations & & & \\
\hline
\end{tabular}

Notes: Panel A presents section-level statistics for De Anza Community College between fall 2002 and summer 2010. Column (1) reports the average share of sections with waitlists, by subject and before sample restrictions. Column (2) reports the same for course sections where at least one student signed up for the waitlist. The STEM definition follows the National Science Foundation. Waitlist length measures how many students remain on the waitlist at the end of the registration period for oversubscribed sections. In Panel B, column (1) describes student characteristics at all two-year colleges in the California, column (2) shows characteristics for De Anza students, and column (3) reports statistics for the students in the analysis within one position of the waitlist cutoff (sample restrictions are detailed in Section 2.3). Data for all two-year public colleges in CA comes from IPEDS for fall 2014, except for financial aid receipt which is from the 2014-2015 school year. In Column (1), financial aid receipt and age represent a cross section of all undergraduates at public two-year schools in California. In Columns (2) and (3), students are counted as receiving aid if they received it at any time in the sample period; age represents their age in their first term in the sample period. The number of courses is the number a student was enrolled in after the drop date in the first observed term. The number of waitlists is the total that a student signed up for during the advanced registration period in the student's first observed term. 
Table 2: Frandsen Manipulation Test for Discrete Running Variables

\begin{tabular}{cr}
$\begin{array}{c}\text { Nonlinearity } \\
\text { Parameter }(k) \\
(1)\end{array}$ & $\begin{array}{r}\text { P-value } \\
(2)\end{array}$ \\
\hline 0.005 & 0.078 \\
0.010 & 0.091 \\
0.015 & 0.115 \\
0.020 & 0.148 \\
0.025 & 0.185 \\
0.030 & 0.234 \\
0.035 & 0.291 \\
0.040 & 0.350 \\
0.045 & 0.416 \\
0.050 & 0.483
\end{tabular}

Notes: This table presents results from the manipulation test proposed in Frandsen (2017). The parameter $k$, which is chosen by the researcher, represents the "maximal degree of nonlinearity in the probability mass function that is still considered to be compatible with no manipulation" (Frandsen, 2017). Column (1) reports tested values of $k$ and Column (2) reports the p-value of a test of the null hypothesis that no manipulation occurred. 
Table 3: Test for Balance of Pre-determined Student Characteristics Across the Waitlist Cutoff

\begin{tabular}{|c|c|c|c|c|c|c|c|c|c|}
\hline & \multicolumn{3}{|c|}{ Bandwidth $=1$} & \multicolumn{3}{|c|}{ Bandwidth $=2$} & \multicolumn{3}{|c|}{ Bandwidth $=3$} \\
\hline & $\begin{array}{l}\text { Coeff } \\
(1)\end{array}$ & $\begin{array}{c}\text { Std Error } \\
(2)\end{array}$ & $\begin{array}{c}\text { P-Value } \\
(3)\end{array}$ & $\begin{array}{c}\text { Coeff } \\
(4)\end{array}$ & $\begin{array}{c}\text { Std Error } \\
(5)\end{array}$ & $\begin{array}{c}\text { P-Value } \\
(6)\end{array}$ & $\begin{array}{c}\text { Coeff } \\
(7)\end{array}$ & $\begin{array}{l}\text { Std Error } \\
(8)\end{array}$ & $\begin{array}{c}\text { P-Value } \\
(9)\end{array}$ \\
\hline Asian & 0.004 & 0.015 & 0.807 & 0.006 & 0.011 & 0.605 & 0.006 & 0.010 & 0.514 \\
\hline Hispanic & 0.018 & 0.011 & 0.103 & 0.007 & 0.008 & 0.393 & 0.008 & 0.007 & 0.264 \\
\hline Black & 0.001 & 0.007 & 0.883 & 0.003 & 0.005 & 0.574 & 0.001 & 0.004 & 0.739 \\
\hline Female & -0.017 & 0.015 & 0.257 & -0.022 & 0.011 & 0.058 & -0.024 & 0.010 & 0.018 \\
\hline Missing Gender & 0.002 & 0.001 & 0.165 & 0.001 & 0.001 & 0.394 & 0.000 & 0.001 & 0.734 \\
\hline Age & 0.351 & 0.199 & 0.078 & 0.250 & 0.151 & 0.098 & 0.341 & 0.132 & 0.010 \\
\hline Missing Age & -0.001 & 0.001 & 0.315 & 0.000 & 0.000 & 0.316 & 0.000 & 0.000 & 0.316 \\
\hline International Student & 0.004 & 0.014 & 0.792 & -0.003 & 0.010 & 0.741 & -0.016 & 0.009 & 0.073 \\
\hline Observations $\left(N_{l} / N_{r}\right)$ & \multicolumn{3}{|c|}{$1,977 / 2,281$} & \multicolumn{3}{|c|}{$3,456 / 4,236$} & \multicolumn{3}{|c|}{$4,488 / 5,849$} \\
\hline
\end{tabular}

Notes: Each row reports results from a linear regression of the covariate on an indicator for missing a waitlist cutoff, term by year fixed effects, registration priority fixed effects, and indicators for special student categories. A bandwidth of one indicates the sample of students within one position of the waitlist cutoff, and so on. For each bandwidth, the first column shows coefficients, the second column shows the robust standard error, and the third column shows the p-value. The p-value in the last row is from an $\mathrm{F}$ test of whether the differences in each characteristic are jointly significant, conditional on the fixed effects and special student categories previously listed. 
Table 4: First Stage Effect of Missing the Waitlist Cutoff on Enrollment in Waitlisted Section and Course

\begin{tabular}{|c|c|c|c|c|c|}
\hline \multicolumn{2}{|c|}{ Bandwidth $=1$} & \multicolumn{2}{|c|}{ Bandwidth $=2$} & \multicolumn{2}{|c|}{ Bandwidth $=3$} \\
\hline (1) & (2) & (3) & (4) & (5) & (6) \\
\hline
\end{tabular}

\begin{tabular}{lcccccc}
\multicolumn{7}{c}{ Panel A: Section Enrollment } \\
Missed WL Cutoff & $-0.641^{* * *}$ & $-0.644^{* * *}$ & $-0.639^{* * *}$ & $-0.641^{* * *}$ & $-0.639^{* * *}$ & $-0.641^{* * *}$ \\
& $(0.011)$ & $(0.011)$ & $(0.008)$ & $(0.008)$ & $(0.007)$ & $(0.007)$ \\
F-Statistic & 3526 & 3583 & 6113 & 6194 & 7929 & 8042 \\
Controls & $\mathrm{N}$ & $\mathrm{Y}$ & $\mathrm{N}$ & $\mathrm{Y}$ & $\mathrm{N}$ & $\mathrm{Y}$ \\
Control Mean & 0.641 & 0.641 & 0.641 & 0.641 & 0.641 & 0.641 \\
& \multicolumn{7}{c}{ Panel B: Course Enrollment } \\
& $-0.645^{* * *}$ & $-0.648^{* * *}$ & $-0.638^{* * *}$ & $-0.639^{* * *}$ & $-0.638^{* * *}$ & $-0.640^{* * *}$ \\
Missed WL Cutoff & $(0.011)$ & $(0.011)$ & $(0.008)$ & $(0.008)$ & $(0.007)$ & $(0.007)$ \\
& \multicolumn{7}{c}{} & & & & \\
& 3516 & 3555 & 5912 & 5958 & 7682 & 7745 \\
F-Statistic & $\mathrm{N}$ & $\mathrm{Y}$ & $\mathrm{N}$ & $\mathrm{Y}$ & $\mathrm{N}$ & $\mathrm{Y}$ \\
Controls & 0.655 & 0.655 & 0.655 & 0.655 & 0.655 & 0.655 \\
Control Mean & $1,977 / 2,281$ & $3,456 / 4,236$ & $4,488 / 5,849$ \\
Observations $\left(N_{l} / N_{r}\right)$ &
\end{tabular}

Notes: Results are from a linear regression where the dependent variable is enrollment in the waitlisted section in Panel A and enrollment in the waitlisted course in Panel B, where enrollment is equal to 1 if the student was enrolled at the end of the advanced registration period. A bandwidth of one indicates the sample of students within one position of the waitlist cutoff, and so on. For each bandwidth, the first column does not include controls whereas the second controls for race/ethnicity, gender, age, citizenship, financial aid receipt, first-time students, special student status, special program status, registration priority fixed effects, term by year fixed effects, and indicators for missing variables. The control mean is the mean of the dependent variable for students with a running variable of zero. Standard errors are robust to heteroskedasticity. $\left({ }^{*} p<0.1,{ }^{* *} p<0.05,{ }^{* * *}\right.$ $p<0.01)$ 
Table 5: Effect of Missing the Waitlist Cutoff on Course Load and Persistence

\section{\# Courses Enrolled in \\ Concurrent Term}

Zer

(1)
One Three or Two or More

(2)
(3)
Enrolled

Next Term

\begin{tabular}{|c|c|c|c|c|}
\hline \multirow[b]{2}{*}{ 2SLS } & \multicolumn{3}{|c|}{ Panel A: Bandwidth $=1$} & \multirow[b]{2}{*}{$\begin{array}{c}-0.019 \\
(0.021) \\
{[0.688]}\end{array}$} \\
\hline & $\begin{array}{l}0.026^{*} \\
(0.014) \\
{[0.104]}\end{array}$ & $\begin{array}{l}-0.008 \\
(0.021) \\
{[0.337]}\end{array}$ & $\begin{array}{c}-0.017 \\
(0.022) \\
{[0.559]}\end{array}$ & \\
\hline Observations $\left(N_{l} / N_{r}\right)$ & \multicolumn{3}{|c|}{$1,977 / 2,281$} & \\
\hline $\mathrm{CCM}$ & $\begin{array}{c}0.023^{* *} \\
(0.011) \\
{[0.104]}\end{array}$ & $\begin{array}{c}0.010 \\
(0.016) \\
{[0.336]}\end{array}$ & $\begin{array}{c}-0.034^{* *} \\
(0.016) \\
{[0.561]}\end{array}$ & $\begin{array}{l}-0.019 \\
(0.016) \\
{[0.672]}\end{array}$ \\
\hline Observations $\left(N_{l} / N_{r}\right)$ & \multicolumn{3}{|c|}{$3,456 / 4,236$} & \\
\hline CCM & $\begin{array}{c}0.028^{* * *} \\
(0.010) \\
{[0.100]}\end{array}$ & $\begin{array}{c}0.023^{*} \\
(0.014) \\
{[0.328]}\end{array}$ & $\begin{array}{c}-0.051^{* * *} \\
(0.014) \\
{[0.571]}\end{array}$ & $\begin{array}{c}-0.028 * * \\
(0.014) \\
{[0.684]}\end{array}$ \\
\hline Observations $\left(N_{l} / N_{r}\right)$ & & $4,488 / 5,8$ & & \\
\hline \multicolumn{5}{|c|}{$\begin{array}{l}\text { Notes: This table shows results from a 2SLS regression as in equation 3. Panel A uses } \\
\text { a bandwidth of one, meaning the sample of students within one position of the waitlist } \\
\text { cutoff, and so on. For each bandwidth, the outcome is an indicator for whether the } \\
\text { student took no courses in the concurrent term in Column (1), took one or two courses } \\
\text { in Column (2), or took three or more courses in Column (3). A course is counted } \\
\text { if the student is enrolled after the add/drop date. The outcome in column (4) is an } \\
\text { indicator for whether the student enrolls in any classes the following major term. The } \\
\text { standard errors are in parentheses, with the control complier means (CCM) displayed } \\
\text { in brackets below. All columns include the covariates listed in Table } 4 \text {. Standard } \\
\text { errors are robust to heteroskedasticity. }\left({ }^{*} p<0.1,{ }^{* *} p<0.05,{ }^{* * *} p<0.01\right)\end{array}$} \\
\hline
\end{tabular}


Table 6: Effect of Missing the Waitlist Cutoff on Transfers

\begin{tabular}{|c|c|c|c|c|c|}
\hline Outcome & $\begin{array}{l}\text { Within } \\
1 \text { Year } \\
\text { (1) }\end{array}$ & $\begin{array}{l}\text { Within } \\
2 \text { Years } \\
(2)\end{array}$ & $\begin{array}{l}\text { Within } \\
3 \text { Years } \\
(3)\end{array}$ & $\begin{array}{l}\text { Within } \\
4 \text { Years } \\
(4)\end{array}$ & $\begin{array}{l}\text { Within } \\
5 \text { Years } \\
(5)\end{array}$ \\
\hline & \multicolumn{5}{|c|}{ Panel A: Bandwidth $=1$} \\
\hline Transfer Other Two-Year & $\begin{array}{l}0.009 \\
(0.011)\end{array}$ & $\begin{array}{c}0.036 * * \\
(0.015)\end{array}$ & $\begin{array}{c}0.026 \\
(0.017)\end{array}$ & $\begin{array}{c}0.026 \\
(0.019)\end{array}$ & $\begin{array}{c}0.027 \\
(0.020)\end{array}$ \\
\hline CCM & {$[0.056]$} & {$[0.105]$} & {$[0.152]$} & {$[0.189]$} & {$[0.222]$} \\
\hline Transfer Four-Year & $\begin{array}{c}0.000 \\
(0.008) \\
{[0.030]}\end{array}$ & $\begin{array}{c}0.009 \\
(0.012) \\
{[0.062]}\end{array}$ & $\begin{array}{c}0.004 \\
(0.017) \\
{[0.141]}\end{array}$ & $\begin{array}{c}0.013 \\
(0.019) \\
{[0.190]}\end{array}$ & $\begin{array}{c}0.019 \\
(0.020) \\
{[0.219]}\end{array}$ \\
\hline Observations $\left(N_{l} / N_{r}\right)$ & \multicolumn{5}{|c|}{$1,977 / 2,281$} \\
\hline $\begin{array}{l}\text { Transfer Other Two-Year } \\
\text { CCM }\end{array}$ & $\begin{array}{l}0.008 \\
(0.009) \\
{[0.067]}\end{array}$ & $\begin{array}{c}0.029 * * \\
(0.012) \\
{[0.118]}\end{array}$ & $\begin{array}{c}0.032^{* *} \\
(0.013) \\
{[0.164]}\end{array}$ & $\begin{array}{c}0.031 * * \\
(0.014) \\
{[0.202]}\end{array}$ & $\begin{array}{l}0.026^{*} \\
(0.015) \\
{[0.233]}\end{array}$ \\
\hline Transfer Four-Year & $\begin{array}{l}0.010^{*} \\
(0.006) \\
{[0.027]}\end{array}$ & $\begin{array}{c}0.011 \\
(0.009) \\
{[0.064]}\end{array}$ & $\begin{array}{c}0.006 \\
(0.013) \\
{[0.143]}\end{array}$ & $\begin{array}{c}0.013 \\
(0.014) \\
{[0.197]}\end{array}$ & $\begin{array}{c}0.015 \\
(0.015) \\
{[0.227]}\end{array}$ \\
\hline Observations $\left(N_{l} / N_{r}\right)$ & \multicolumn{5}{|c|}{$3,456 / 4,236$} \\
\hline Transfer Other Two-Year & $\begin{array}{l}0.014^{*} \\
(0.008) \\
{[0.067]}\end{array}$ & $\begin{array}{c}0.032^{* * *} \\
(0.010) \\
{[0.113]}\end{array}$ & $\begin{array}{c}0.032^{* * *} \\
(0.011) \\
{[0.161]}\end{array}$ & $\begin{array}{c}0.034^{* * *} \\
(0.012) \\
{[0.198]}\end{array}$ & $\begin{array}{c}0.032^{* *} \\
(0.013) \\
{[0.226]}\end{array}$ \\
\hline Transfer Four-Year & $\begin{array}{c}0.008 \\
(0.005) \\
{[0.028]}\end{array}$ & $\begin{array}{c}0.013 \\
(0.008) \\
{[0.064]}\end{array}$ & $\begin{array}{c}0.004 \\
(0.011) \\
{[0.140]}\end{array}$ & $\begin{array}{c}0.005 \\
(0.012) \\
{[0.196]}\end{array}$ & $\begin{array}{c}0.002 \\
(0.013) \\
{[0.227]}\end{array}$ \\
\hline Observations $\left(N_{l} / N_{r}\right)$ & \multicolumn{5}{|c|}{$4,488 / 5,849$} \\
\hline
\end{tabular}

Notes: This table shows results from a 2SLS regression as in equation 3. Panel A uses a bandwidth of one, meaning the sample of students within one position of the waitlist cutoff, and so on. For each bandwidth, the outcomes are indicators for transferring at different time horizons: within one through five years of the waitlisted term. The standard errors are in parentheses, with the control complier means (CCM) displayed in brackets below. All columns include the covariates listed in Table 4. Standard errors are robust to heteroskedasticity. (* $\left.p<0.1,{ }^{* *} p<0.05,{ }^{* * *} p<0.01\right)$ 
Table 7: Effect of Missing the Waitlist Cutoff on Degree Completion

Within Within Within Within Within

1 Year 2 Years 3 Years 4 Years 5 Years

\begin{tabular}{lccccc} 
Outcome & $(1)$ & $(2)$ & $(3)$ & $(4)$ & $(5)$ \\
\hline \multirow{5}{*}{ Panel A: Bandwidth $=1$} \\
Certificate/Associate's & 0.003 & -0.002 & -0.010 & -0.016 & -0.011 \\
& $(0.005)$ & $(0.009)$ & $(0.013)$ & $(0.015)$ & $(0.015)$ \\
CCM & {$[0.008]$} & {$[0.033]$} & {$[0.077]$} & {$[0.106]$} & {$[0.117]$} \\
& 0.004 & 0.002 & 0.006 & -0.003 & -0.002 \\
Bachelor's & $(0.003)$ & $(0.003)$ & $(0.006)$ & $(0.010)$ & $(0.014)$ \\
CCM & {$[0.002]$} & {$[0.006]$} & {$[0.014]$} & {$[0.043]$} & {$[0.094]$}
\end{tabular}

Observations $\left(N_{l} / N_{r}\right) \quad 1,977 / 2,281$

Panel B: Bandwidth = 2

$\begin{array}{cccccc}\text { Certificate/Associate's } & 0.001 & -0.002 & -0.008 & -0.009 & -0.005 \\ & (0.003) & (0.007) & (0.010) & (0.011) & (0.011) \\ \text { CCM } & {[0.009]} & {[0.034]} & {[0.077]} & {[0.103]} & {[0.115]}\end{array}$

$\begin{array}{cccccc}\text { Bachelor's } & 0.002 & 0.004 & 0.006 & 0.005 & -0.002 \\ & (0.002) & (0.003) & (0.004) & (0.008) & (0.011) \\ \text { CCM } & {[0.002]} & {[0.005]} & {[0.013]} & {[0.045]} & {[0.101]}\end{array}$

Observations $\left(N_{l} / N_{r}\right) \quad 3,456 / 4,236$

Panel $C:$ Bandwidth $=3$

$\begin{array}{llllll}\text { Certificate/Associate's } & -0.002 & -0.008 & -0.013 & -0.015 & -0.009\end{array}$

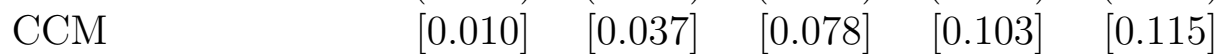

$\begin{array}{llllll}\text { Bachelor's } & 0.001 & 0.001 & 0.005 & 0.003 & -0.005\end{array}$

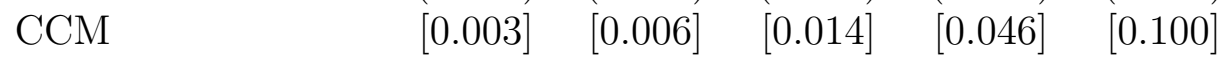

Observations $\left(N_{l} / N_{r}\right) \quad 4,488 / 5,849$

Notes: This table shows results from a 2SLS regression as in equation 3. Panel A uses a bandwidth of one, meaning the sample of students within one position of the waitlist cutoff, and so on. For each bandwidth, the outcomes are indicators for degree completion at different time horizons: within one through five years of the waitlisted term. Associate's and certificate completion data comes from both De Anza administrative records and the National Student Clearinghouse.The standard errors are in parentheses, with the control complier means (CCM) displayed in brackets below. All columns include the covariates listed in Table 4. Standard errors are robust to heteroskedasticity. ( $\left.{ }^{*} p<0.1,{ }^{* *} p<0.05,{ }^{* * *} p<0.01\right)$ 
Table 8: Effect of Missing the Waitlist Cutoff on Transfers and Degree Completion, by Ethnicity

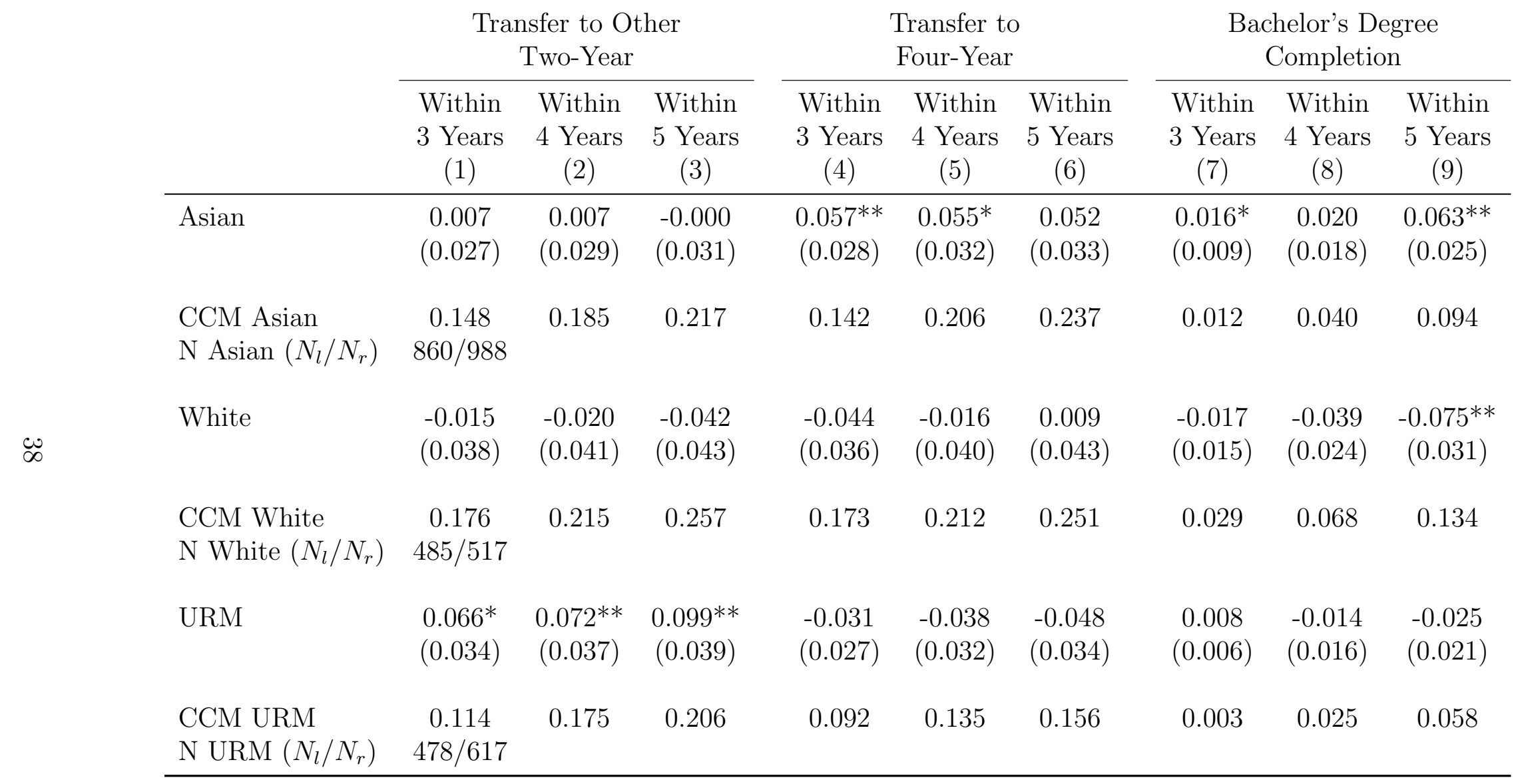

Notes: This table shows results from a 2SLS regression as in equation 3, using a bandwidth of one, where effects are estimated separately by ethnicity. The outcomes are indicators for transfers to other two-year schools, transfers to four-year schools, and bachelor's degree completion at different time horizons: within three through five years of the waitlisted term. The standard errors are in parentheses, with the control complier means (CCM) and p-value from a test for the difference in point estimates between groups displayed below. All columns include the covariates listed in Table 4. Standard errors are robust to heteroskedasticity. $\left(* p<0.1,{ }^{* *} p<0.05\right.$, ${ }^{* * *}$ $p<0.01)$ 
Figure 1: A Hypothetical Registration Log

\begin{tabular}{cccc|ccc}
\hline$P_{i}$ & action & date & time & $X_{i}$ & $D_{i}$ & $R V_{i}$ \\
\hline$\vdots$ & $\vdots$ & $\vdots$ & $\vdots$ & $\vdots$ & $\vdots$ & $\vdots$ \\
36 & enroll & Aug 1, 2004 & $11: 00: 00$ & - & - & - \\
37 & enroll & Aug 1, 2004 & $12: 00: 00$ & - & - & - \\
38 & enroll & Aug 1, 2004 & $13: 00: 00$ & - & - & - \\
39 & enroll & Aug 1, 2004 & $14: 00: 00$ & - & - & - \\
40 & enroll & Aug 1, 2004 & $15: 00: 00$ & - & - & - \\
38 & drop & Aug 2, 2004 & $8: 00: 00$ & - & - & - \\
41 & enroll & Aug 2, 2004 & $10: 00: 00$ & - & - & - \\
42 & waitlist & Aug 2, 2004 & $12: 00: 00$ & 1 & 2 & -1 \\
43 & waitlist & Aug 2, 2004 & $13: 00: 00$ & 2 & 2 & 0 \\
44 & waitlist & Aug 2, 2004 & $14: 00: 00$ & 3 & 2 & 1 \\
7 & drop & Aug 3, 2004 & $20: 00: 00$ & - & - & - \\
42 & enroll & Aug 3, 2004 & $21: 00: 00$ & - & - & - \\
22 & drop & Aug 4, 2004 & $9: 00: 00$ & - & - & - \\
43 & enroll & Aug 4, 2004 & $11: 00: 00$ & - & - & - \\
44 & drop & Aug 4, 2004 & $15: 00: 00$ & - & - & - \\
45 & waitlist & Aug 4, 2004 & $17: 00: 00$ & 1 & 0 & 1 \\
\hline
\end{tabular}

Notes. $P_{i}$ is a student identifier, $X_{i}$ is the initial waitlist position, $D_{i}$ counts the number of students who signed up before student $i$ signed up for the waitlist, and dropped after student $i$ (as long as it was during the registration period). $R V_{i}=X_{i}-D_{i}$ is student $i$ 's running variable. 
Figure 2: Density of the Running Variable

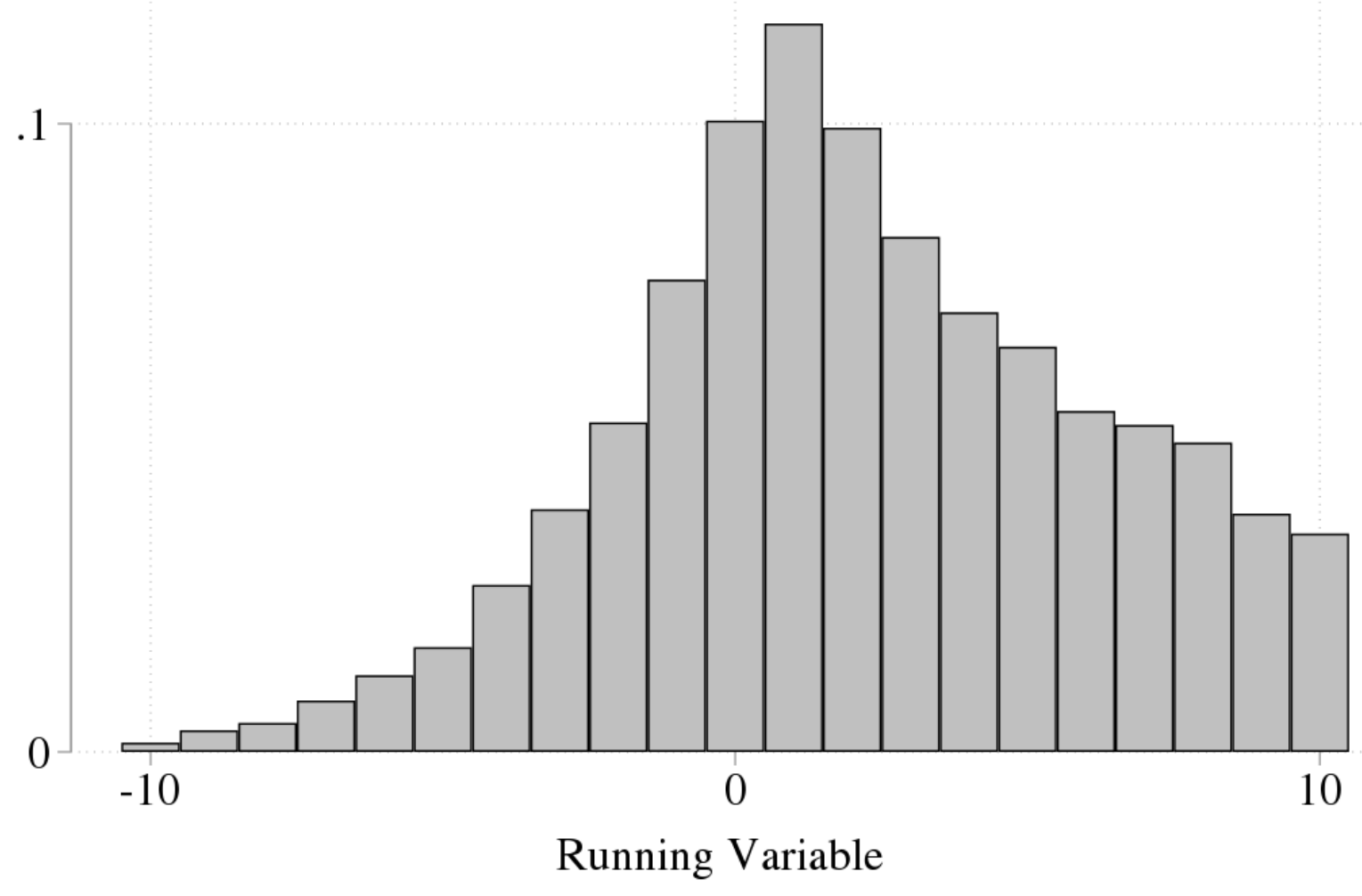


Figure 3: First Stage Effect of Missing the Waitlist Cutoff on Enrollment in Waitlisted Section and Course

(a) Enrolled in Waitlisted Section

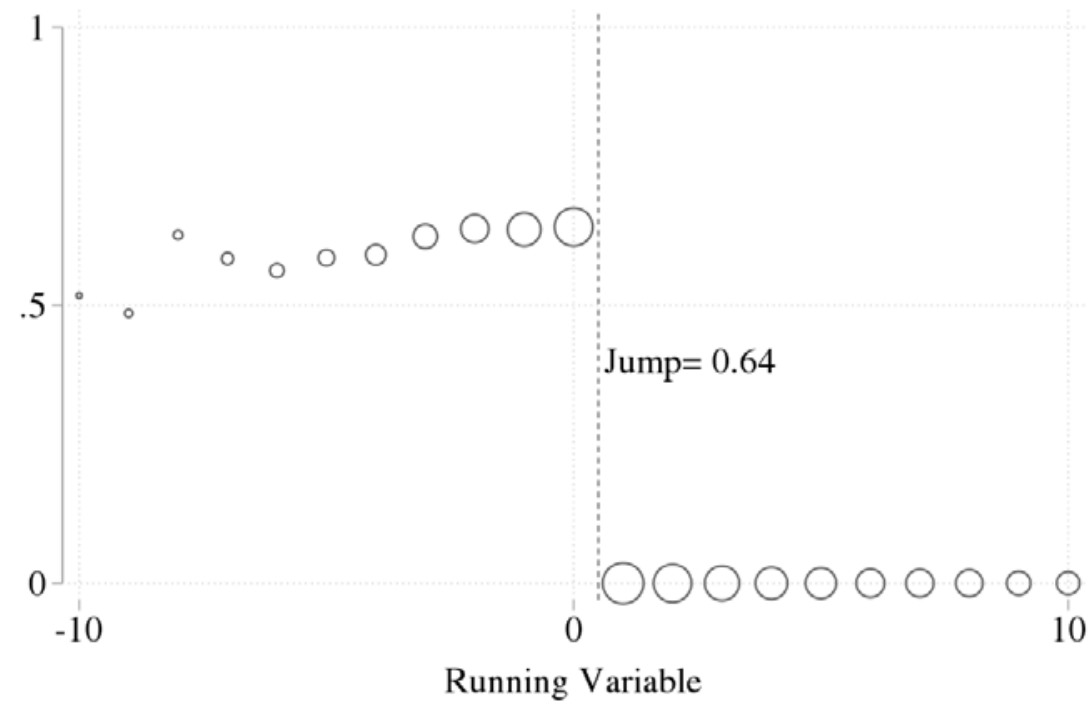

(b) Enrolled in Waitlisted Course

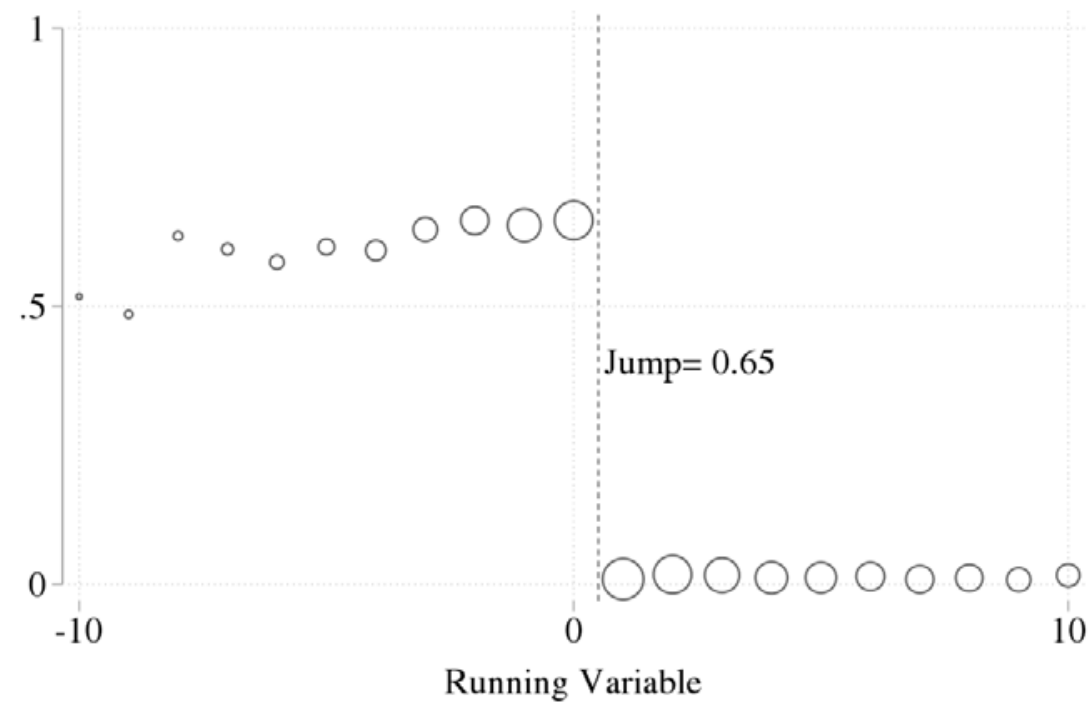

Notes. Each dot represents enrollment binned by the value of the running variable, where enrollment is equal to 1 if the student was enrolled in the section or course at the end of the advanced registration period. Both section and course enrollment are equal to 0 for students with a running variable greater than zero by construction. The size of the dot reflects the number of observations in each bin. 
Figure 4: Reduced Form Effect of Missing a Placebo Cutoff

(a) Enrolled in Zero Courses

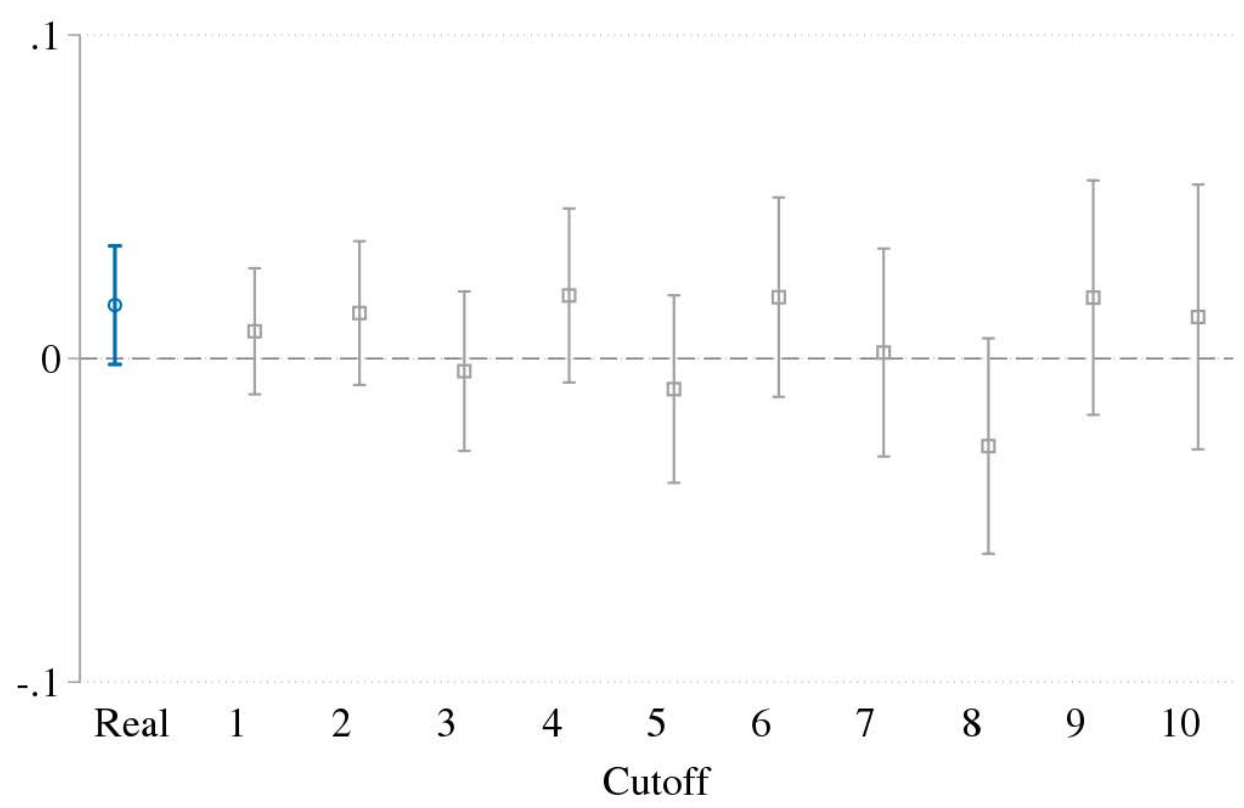

(b) Transferred to Another Two-Year School within Two Years

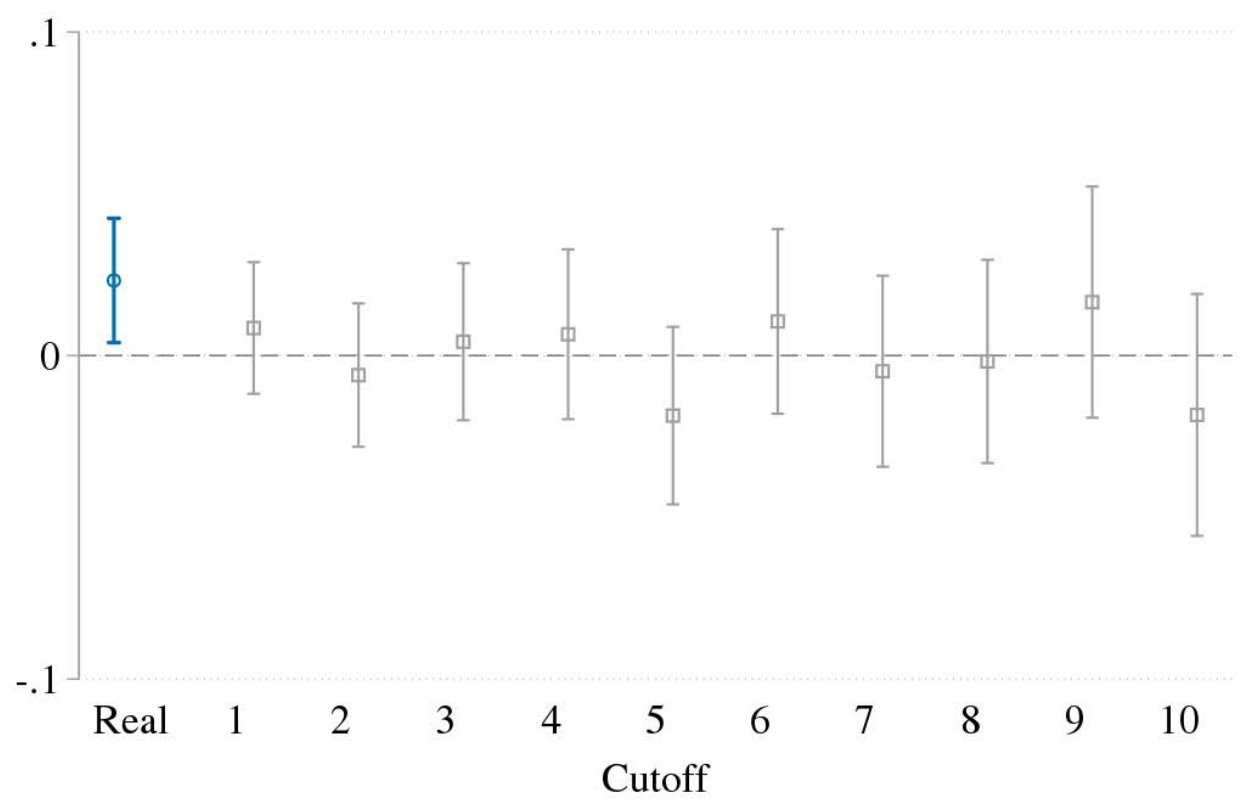

Notes. This figure plots point estimates and confidence intervals for the reduced form effect of missing a placebo cutoff using a bandwidth of one. For example, at the placebo cutoff of three, we show the effect of having a running variable of three relative to a running variable of four. The actual reduced form effect-where the cutoff is equal to zero - is shown in blue, whereas the other values on the $\mathrm{x}$-axis represent the effects of the other placebo cutoffs. 


\section{A Supplemental Tables}

Table A1: Student Initial Education Goal

\begin{tabular}{lcl}
\hline $\begin{array}{l}\text { Included in } \\
\text { Sample }\end{array}$ & Code & Description \\
\hline Yes & A & Obtain an associate's degree and transfer to a four-year institution \\
Yes & B & Transfer to a four-year institution without an associate degree \\
Yes & C & Obtain a two-year associate's degree without transfer \\
& D & Obtain a two-year vocational degree without transfer \\
& E & Earn a vocational certificate without transfer \\
& F & Discover/formulate career interests, plans, goals \\
& G & Prepare for a new career (acquire job skills) \\
& H & Advance in current job/career (update job skills) \\
& I & Maintain certificate or license (e.g., nursing, real estate) \\
& J & Educational development (intellectual, cultural); often \\
& K & Impreational course-takers \\
& L & Complete credits for high school diploma or GED; often \\
& & high school students \\
& M & Undecided on goal \\
N & To move from noncredit coursework to credit course work \\
O & Four-year college student taking courses to meet four-year college \\
& requirement & Uncollected/unreported \\
Y & Not applicable
\end{tabular}

Notes: At application, students are asked to indicate their initial educational goal from the above list. The sample is restricted to community college students who might consider a bachelor's degree at a four-year institution a reasonable substitute to their current program. 
Table A2: Effect of Missing the Waitlist Cutoff on Transfers to Nearby Two-Year Schools within Two Years

\begin{tabular}{lcccc} 
Futcome & $\begin{array}{c}\text { Evergreen } \\
\text { Valley } \\
(1)\end{array}$ & $\begin{array}{c}\text { San Jose } \\
\text { City } \\
\text { 2SLS }\end{array}$ & $\begin{array}{c}\text { Other } \\
\text { Two-Year } \\
(3)\end{array}$ & $\begin{array}{c}(4) \\
\text { CCM }\end{array}$ \\
$\begin{array}{lcccc}-0.008 \\
(0.010)\end{array}$ & $\begin{array}{c}0.013^{* *} \\
(0.006)\end{array}$ & $\begin{array}{c}0.015^{* *} \\
(0.006)\end{array}$ & $\begin{array}{c}0.017^{* *} \\
(0.008)\end{array}$ \\
Observations $\left(N_{l} / N_{r}\right)$ & 1,977 & 2,281 & & 0.013 \\
\hline
\end{tabular}

Notes: This table shows results from a 2SLS regression as in equation 3. The outcomes are indicators for whether the student transferred to Foothill College within two years of the waitlist in Column (1), Evergreen Valley College in Column (2), San Jose City College in Column (3), and any other two-year college in Column (4). The standard errors are in parentheses, with the control complier means $(\mathrm{CCM})$ and the reduced form displayed below. All columns include the covariates listed in Table 4. Standard errors are robust to heteroskedasticity. $(* p<0.1, * *$ $\left.p<0.05,{ }^{* * *} p<0.01\right)$ 
Table A3: Effect of Missing the Waitlist Cutoff on Course Load and Persistence, by Gender

\begin{tabular}{|c|c|c|c|c|}
\hline & \multicolumn{3}{|c|}{ \# Courses Enrolled in Concurrent Term } & \multirow{2}{*}{$\begin{array}{c}\text { Enrolled } \\
\text { Next Term } \\
\text { (4) }\end{array}$} \\
\hline & $\begin{array}{l}\text { Zero } \\
(1)\end{array}$ & $\begin{array}{c}\text { One or Two } \\
(2)\end{array}$ & $\begin{array}{c}\text { Three or More } \\
(3)\end{array}$ & \\
\hline Male & $\begin{array}{c}0.016 \\
(0.020)\end{array}$ & $\begin{array}{c}0.014 \\
(0.031)\end{array}$ & $\begin{array}{l}-0.030 \\
(0.032)\end{array}$ & $\begin{array}{l}-0.004 \\
(0.030)\end{array}$ \\
\hline $\begin{array}{l}\text { CCM Male } \\
\text { N Male }\left(N_{l} / N_{r}\right)\end{array}$ & $\begin{array}{c}0.108 \\
963 / 1,142\end{array}$ & 0.310 & 0.581 & 0.689 \\
\hline Female & $\begin{array}{l}0.034^{*} \\
(0.021)\end{array}$ & $\begin{array}{l}-0.028 \\
(0.029)\end{array}$ & $\begin{array}{l}-0.006 \\
(0.029)\end{array}$ & $\begin{array}{l}-0.031 \\
(0.029)\end{array}$ \\
\hline $\begin{array}{l}\text { CCM Female } \\
\text { N Female }\left(N_{l} / N_{r}\right)\end{array}$ & $\begin{array}{c}0.100 \\
1,012 / 1,131\end{array}$ & 0.362 & 0.537 & 0.687 \\
\hline$P$-value Male $=$ Female & 0.530 & 0.313 & 0.575 & 0.525 \\
\hline
\end{tabular}

Notes: This table shows results from a 2SLS regression as in equation 3 using a bandwidth of one, where effects are estimated separately by gender. The outcome is an indicator for whether the student took no courses in the concurrent term in Column (1), took one or two courses in Column (2), or took three or more courses in Column (3). A course is counted if the student is enrolled after the add/drop date. The outcome in Column (4) is an indicator for whether the student enrolls in any classes the following major term. The standard errors are in parentheses, with the control complier means $(\mathrm{CCM})$ and p-value from a test for the difference in point estimates between groups displayed below. All columns include the covariates listed in Table 4. Standard errors are robust to heteroskedasticity. $\left({ }^{*} p<0.1,{ }^{* *} p<0.05,{ }^{* * *} p<0.01\right)$ 
Table A4: Effect of Missing the Waitlist Cutoff on Course Load and Persistence, by Ethnicity

\begin{tabular}{|c|c|c|c|c|}
\hline & \multicolumn{3}{|c|}{ \# Courses Enrolled in Concurrent Term } & \multirow{2}{*}{$\begin{array}{c}\text { Enrolled } \\
\text { Next Term } \\
(4)\end{array}$} \\
\hline & $\begin{array}{c}\text { Zero } \\
(1)\end{array}$ & $\begin{array}{c}\text { One or Two } \\
(2)\end{array}$ & $\begin{array}{c}\text { Three or More } \\
(3)\end{array}$ & \\
\hline Asian & $\begin{array}{c}0.027 \\
(0.022)\end{array}$ & $\begin{array}{l}-0.006 \\
(0.032)\end{array}$ & $\begin{array}{l}-0.022 \\
(0.033)\end{array}$ & $\begin{array}{l}-0.023 \\
(0.031)\end{array}$ \\
\hline $\begin{array}{l}\text { CCM Asian } \\
\mathrm{N} \text { Asian }\left(N_{l} / N_{r}\right)\end{array}$ & $\begin{array}{c}0.094 \\
860 / 988\end{array}$ & 0.287 & 0.619 & 0.758 \\
\hline White & $\begin{array}{c}0.022 \\
(0.032)\end{array}$ & $\begin{array}{c}0.013 \\
(0.046)\end{array}$ & $\begin{array}{l}-0.035 \\
(0.047)\end{array}$ & $\begin{array}{l}-0.047 \\
(0.046)\end{array}$ \\
\hline $\begin{array}{l}\text { CCM White } \\
\text { N White }\left(N_{l} / N_{r}\right)\end{array}$ & $\begin{array}{c}0.121 \\
484 / 517\end{array}$ & 0.362 & 0.518 & 0.654 \\
\hline URM & $\begin{array}{l}-0.000 \\
(0.027)\end{array}$ & $\begin{array}{l}-0.016 \\
(0.041)\end{array}$ & $\begin{array}{c}0.017 \\
(0.042)\end{array}$ & $\begin{array}{c}0.034 \\
(0.042)\end{array}$ \\
\hline $\begin{array}{l}\text { CCM URM } \\
\mathrm{N} \operatorname{URM}\left(N_{l} / N_{r}\right)\end{array}$ & $\begin{array}{c}0.101 \\
478 / 617\end{array}$ & 0.390 & 0.509 & 0.623 \\
\hline $\begin{array}{l}\text { P-value White }=\text { Asian } \\
\text { P-value URM }=\text { Asian } \\
\text { P-value URM }=\text { White }\end{array}$ & $\begin{array}{l}0.885 \\
0.425 \\
0.598\end{array}$ & $\begin{array}{l}0.737 \\
0.841 \\
0.635\end{array}$ & $\begin{array}{l}0.820 \\
0.477 \\
0.416\end{array}$ & $\begin{array}{l}0.659 \\
0.274 \\
0.190\end{array}$ \\
\hline
\end{tabular}

Notes: This table shows results from a 2SLS regression as in equation 3 using a bandwidth of one, where effects are estimated separately by ethnicity. The outcome is an indicator for whether the student took no courses in the concurrent term in Column (1), took one or two courses in Column (2), or took three or more courses in Column (3). A course is counted if the student is enrolled after the add/drop date. The outcome in Column (4) is an indicator for whether the student enrolls in any classes the following major term. The standard errors are in parentheses, with the control complier means (CCM) and p-value from a test for the difference in point estimates between groups displayed below. All columns include the covariates listed in Table 4. Standard errors are robust to heteroskedasticity. $\left({ }^{*} p<0.1,{ }^{* *} p<0.05,{ }^{* * *} p<0.01\right)$ 
Table A5: Effect of Missing the Waitlist Cutoff on Course Load and Persistence, by Course Popularity

\begin{tabular}{lcccc} 
& \multicolumn{2}{c}{ \# Courses Enrolled in Concurrent Term } & Enrolled \\
\cline { 2 - 4 } & Zero & One or Two & Three or More & Next Term \\
& $(1)$ & $(2)$ & $(3)$ & $(4)$ \\
\hline Top 5 & 0.057 & $-0.107^{*}$ & 0.050 & -0.008 \\
& $(0.037)$ & $(0.064)$ & $(0.066)$ & $(0.066)$ \\
CCM Top 5 & 0.071 & 0.304 & 0.625 & 0.705 \\
N Top $5\left(N_{l} / N_{r}\right)$ & $170 / 209$ & & & \\
Other Courses & 0.024 & 0.003 & -0.027 & -0.025 \\
& $(0.015)$ & $(0.022)$ & $(0.023)$ & $(0.022)$ \\
CCM Other & 0.107 & 0.340 & 0.552 & 0.687 \\
N Other $\left(N_{l} / N_{r}\right)$ & $1,807 / 2,072$ & & & \\
P-value Top $5=$ Other & 0.401 & 0.106 & 0.274 & 0.803 \\
\hline
\end{tabular}

Notes: This table shows results from a 2SLS regression as in equation 3 using a bandwidth of one, where effects are estimated separately by popularity of the course. Top five courses are those that are the most frequently requested. The outcome is an indicator for whether the student took no courses in the concurrent term in Column (1), took one or two courses in Column (2), or took three or more courses in Column (3). A course is counted if the student is enrolled after the add/drop date. The outcome in Column (4) is an indicator for whether the student enrolls in any classes the following major term. The standard errors are in parentheses, with the control complier means (CCM) and p-value from a test for the difference in point estimates between groups displayed below. All columns include the covariates listed in Table 4. Standard errors are robust to heteroskedasticity. ${ }^{*} p<0.1$, $\left.{ }^{* *} p<0.05,{ }^{* * *} p<0.01\right)$ 
Table A6: Effect of Missing the Waitlist Cutoff on Course Load and Persistence, by Waitlisted Subject

\begin{tabular}{|c|c|c|c|c|}
\hline & \multicolumn{3}{|c|}{ \# Courses Enrolled in Concurrent Term } & \multirow{2}{*}{$\begin{array}{c}\text { Enrolled } \\
\text { Next Term } \\
\quad(4)\end{array}$} \\
\hline & $\begin{array}{c}\text { Zero } \\
(1)\end{array}$ & $\begin{array}{l}\text { One or Two } \\
(2)\end{array}$ & $\begin{array}{l}\text { Three or More } \\
\text { (3) }\end{array}$ & \\
\hline STEM & $\begin{array}{c}0.007 \\
(0.024)\end{array}$ & $\begin{array}{c}0.018 \\
(0.035)\end{array}$ & $\begin{array}{l}-0.025 \\
(0.036)\end{array}$ & $\begin{array}{l}-0.011 \\
(0.034)\end{array}$ \\
\hline $\begin{array}{l}\text { CCM STEM } \\
\operatorname{N~STEM~}\left(N_{l} / N_{r}\right)\end{array}$ & $\begin{array}{c}0.098 \\
678 / 771\end{array}$ & 0.294 & 0.607 & 0.738 \\
\hline Arts/Humanities & $\begin{array}{c}0.053^{* *} \\
(0.027)\end{array}$ & $\begin{array}{l}-0.051 \\
(0.038)\end{array}$ & $\begin{array}{l}-0.002 \\
(0.039)\end{array}$ & $\begin{array}{c}0.021 \\
(0.039)\end{array}$ \\
\hline $\begin{array}{l}\text { CCM Arts/Hum. } \\
\text { N Arts/Hum. }\left(N_{l} / N_{r}\right)\end{array}$ & $\begin{array}{c}0.099 \\
542 / 663\end{array}$ & 0.347 & 0.554 & 0.649 \\
\hline Social Studies & $\begin{array}{l}-0.015 \\
(0.041)\end{array}$ & $\begin{array}{l}-0.007 \\
(0.062)\end{array}$ & $\begin{array}{c}0.023 \\
(0.062)\end{array}$ & $\begin{array}{l}-0.092 \\
(0.062)\end{array}$ \\
\hline $\begin{array}{l}\text { CCM Soc. Stud. } \\
\text { N Soc. Stud. }\left(N_{l} / N_{r}\right)\end{array}$ & $\begin{array}{c}0.129 \\
242 / 261\end{array}$ & 0.355 & 0.516 & 0.658 \\
\hline Other & $\begin{array}{l}0.050^{*} \\
(0.030)\end{array}$ & $\begin{array}{c}0.013 \\
(0.043)\end{array}$ & $\begin{array}{l}-0.063 \\
(0.044)\end{array}$ & $\begin{array}{l}-0.033 \\
(0.042)\end{array}$ \\
\hline $\begin{array}{l}\text { CCM Other } \\
\text { N Other }\left(N_{l} / N_{r}\right)\end{array}$ & $\begin{array}{c}0.105 \\
515 / 586\end{array}$ & 0.373 & 0.521 & 0.680 \\
\hline P-value STEM=Arts/Hum & 0.194 & 0.178 & 0.663 & 0.532 \\
\hline P-value STEM=Soc. Stud. & 0.646 & 0.717 & 0.509 & 0.255 \\
\hline P-value STEM=Other & 0.261 & 0.928 & 0.500 & 0.689 \\
\hline P-value Arts/Hum = Soc. Stud & 0.164 & 0.545 & 0.742 & 0.124 \\
\hline P-value Arts/Hum= Other & 0.940 & 0.264 & 0.295 & 0.348 \\
\hline P-value Soc. Stud.=Other & 0.203 & 0.785 & 0.259 & 0.433 \\
\hline
\end{tabular}

Notes: This table shows results from a 2SLS regression as in equation 3 using a bandwidth of one, where effects are estimated separately by the subject of the waitlisted course. The outcome is an indicator for whether the student took no courses in the concurrent term in Column (1), took one or two courses in Column (2), or took three or more courses in Column (3). A course is counted if the student is enrolled after the add/drop date. The outcome in Column (4) is an indicator for whether the student enrolls in any classes the following major term. The standard errors are in parentheses, with the control complier means (CCM) and p-value from a test for the difference in point estimates between groups displayed below. All columns include the covariates listed in Table 4. Standard errors are robust to heteroskedasticity. $(* p<0.1$, ** $\left.p<0.05,{ }^{* * *} p<0.01\right)$ 
Table A7: Reduced Form Effect of Missing a Placebo Cutoff

\begin{tabular}{|c|c|c|c|}
\hline Cutoff & $\begin{array}{c}\text { Enrolled in } \\
\text { Zero Courses, } \\
\text { Concurrent Term } \\
(1)\end{array}$ & $\begin{array}{c}\text { Transfer to } \\
\text { Other } 2 \text { Year, } \\
\text { Within } 2 \text { Years } \\
(2)\end{array}$ & $\begin{array}{c}\text { Observations } \\
\left(N_{l} / N_{r}\right) \\
(3)\end{array}$ \\
\hline 0 (Real) & $\begin{array}{l}0.016^{*} \\
(0.009)\end{array}$ & $\begin{array}{c}0.023^{* *} \\
(0.010)\end{array}$ & $1,977 / 2,281$ \\
\hline 1 & $\begin{array}{c}0.008 \\
(0.010)\end{array}$ & $\begin{array}{c}0.009 \\
(0.010)\end{array}$ & $2,281 / 1,955$ \\
\hline 2 & $\begin{array}{c}0.014 \\
(0.011)\end{array}$ & $\begin{array}{c}-0.006 \\
(0.011)\end{array}$ & $1,955 / 1,613$ \\
\hline 3 & $\begin{array}{c}-0.004 \\
(0.013)\end{array}$ & $\begin{array}{c}0.004 \\
(0.012)\end{array}$ & $1,613 / 1,377$ \\
\hline 4 & $\begin{array}{c}0.019 \\
(0.014)\end{array}$ & $\begin{array}{c}0.007 \\
(0.013)\end{array}$ & $1,377 / 1,269$ \\
\hline 5 & $\begin{array}{l}-0.009 \\
(0.015)\end{array}$ & $\begin{array}{c}-0.019 \\
(0.014)\end{array}$ & $1,269 / 1,068$ \\
\hline 6 & $\begin{array}{c}0.019 \\
(0.016)\end{array}$ & $\begin{array}{c}0.011 \\
(0.015)\end{array}$ & $1,068 / 1,024$ \\
\hline 7 & $\begin{array}{c}0.002 \\
(0.016)\end{array}$ & $\begin{array}{l}-0.005 \\
(0.015)\end{array}$ & $1,024 / 969$ \\
\hline 8 & $\begin{array}{l}-0.027 \\
(0.017)\end{array}$ & $\begin{array}{c}-0.002 \\
(0.016)\end{array}$ & $969 / 746$ \\
\hline 9 & $\begin{array}{c}0.019 \\
(0.018)\end{array}$ & $\begin{array}{c}0.016 \\
(0.018)\end{array}$ & $746 / 684$ \\
\hline 10 & $\begin{array}{c}0.013 \\
(0.021)\end{array}$ & $\begin{array}{c}-0.018 \\
(0.019)\end{array}$ & $684 / 579$ \\
\hline
\end{tabular}

Notes: This table shows the coefficient from a regression of the outcome on an indicator for missing the placebo cutoff, equal to one if the student has the running variable of the cutoff plus one. For each row, the sample includes only students with running variable equal to the cutoff value and one plus the cutoff. The outcome in Column (1) is an indicator for being enrolled in zero courses after drop date in the waitlisted term. The outcome in Column (2) is an indicator for being enrolled in another two-year school within two years. All columns include the covariates listed in Table 4. Standard errors are robust to heteroskedasticity. $\left({ }^{*} p<0.1,{ }^{* *} p<0.05\right.$, $* * * \quad p<0.01)$ 
Table A8: Robustness Checks

\begin{tabular}{|c|c|c|c|c|c|c|c|}
\hline Outcome & $\begin{array}{c}\text { No Sample } \\
\text { Restrictions } \\
\text { (1) }\end{array}$ & $\begin{array}{l}\text { Intend to } \\
\text { Transfer } \\
\quad(2)\end{array}$ & $\begin{array}{c}\text { Post } 2007 \\
(3)\end{array}$ & $\begin{array}{c}\text { Course } \\
\text { Enrollment } \\
(4)\end{array}$ & $\begin{array}{c}\text { Section by } \\
\text { Term FE } \\
\text { (5) }\end{array}$ & $\begin{array}{l}\text { Unique } \\
\text { RV's } \\
(6)\end{array}$ & $\begin{array}{c}\text { Linear RV } \\
\text { Control } \\
(7)\end{array}$ \\
\hline Enrolled in 1-2 Courses & $\begin{array}{c}0.003 \\
(0.005)\end{array}$ & $\begin{array}{c}0.005 \\
(0.006)\end{array}$ & $\begin{array}{l}-0.007 \\
(0.008)\end{array}$ & $\begin{array}{l}-0.008 \\
(0.021)\end{array}$ & $\begin{array}{c}0.036 \\
(0.048)\end{array}$ & $\begin{array}{l}-0.006 \\
(0.022)\end{array}$ & $\begin{array}{l}-0.003 \\
(0.016)\end{array}$ \\
\hline Enrolled in $3+$ Courses & $\begin{array}{c}-0.015^{* * *} \\
(0.005)\end{array}$ & $\begin{array}{c}-0.017^{* * *} \\
(0.007)\end{array}$ & $\begin{array}{c}-0.012 \\
(0.008)\end{array}$ & $\begin{array}{c}-0.017 \\
(0.021)\end{array}$ & $\begin{array}{c}-0.099 * * \\
(0.049)\end{array}$ & $\begin{array}{l}-0.029 \\
(0.022)\end{array}$ & $\begin{array}{l}-0.020 \\
(0.017)\end{array}$ \\
\hline Observations $\left(N_{l} / N_{r}\right)$ & $30,329 / 37,103$ & $17,338 / 20,873$ & $11,932 / 14,533$ & $1,977 / 2,281$ & $646 / 696$ & $1,710 / 1,967$ & $6,659 / 12,986$ \\
\hline
\end{tabular}

Notes: This table shows the coefficient from a 2SLS regression as in equation 3 using a bandwidth of one. Column (1) includes all students and all waitlists. Column (2) includes only students who declared an intention to transfer to a four year school upon enrolling at De Anza, and all waitlists. Column (3) restricts the sample to observations after 2007 and, to increase statistical power, includes all students and all waitlists. Column (4) uses the sample in the main analysis but uses the waitlist cutoff to instrument for course enrollment, rather than course section enrollment. Column (5) uses the sample in the main analysis but includes section by term fixed effects. Column (6) includes all of the main sample restrictions but further limits the sample to be unique at the course section by running variable level by keeping the earliest student to register for the waitlist at each value of the running variable in a given course section. Column (7) includes all sample restrictions but uses a linear running variable control and a bandwidth of 10 . All columns include the covariates listed in Table 4. Standard errors are clustered at the student level when more than one observation per student is used, and are robust to heteroskedasticity otherwise. $\left({ }^{*} p<0.1,{ }^{* *} p<0.05,{ }^{* * *} p<0.01\right)$ 
Figure A1: Reduced Form Effect of Missing the Waitlist Cutoff on Course Load and Persistence

(a) Enrolled in Zero Courses

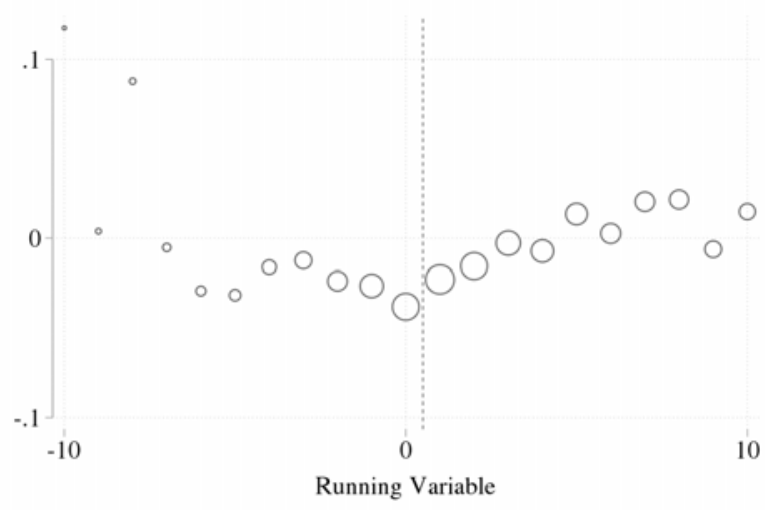

(c) Enrolled in Three or More Courses

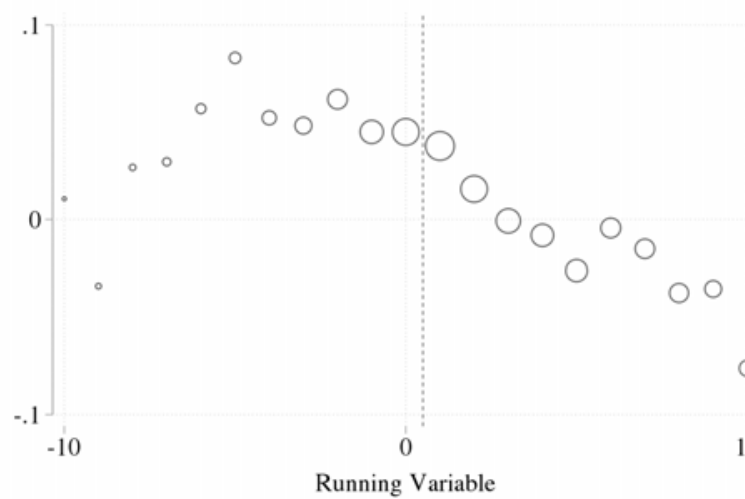

(b) Enrolled in One or Two Courses

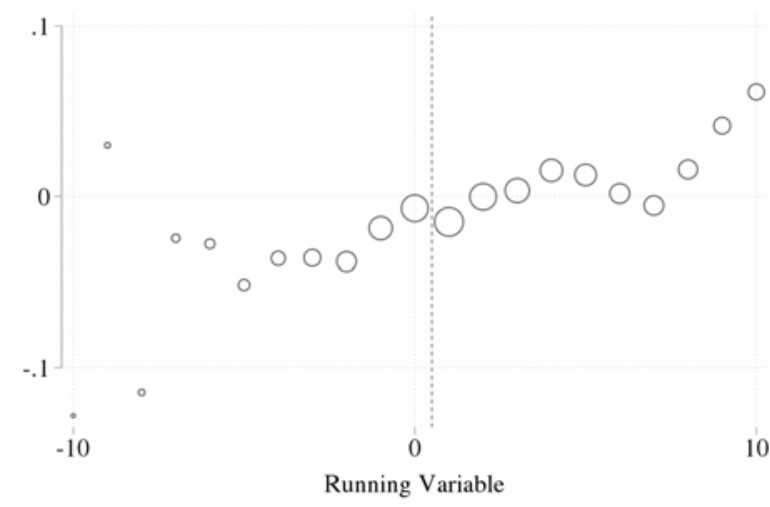

(d) Enrolled Next Term

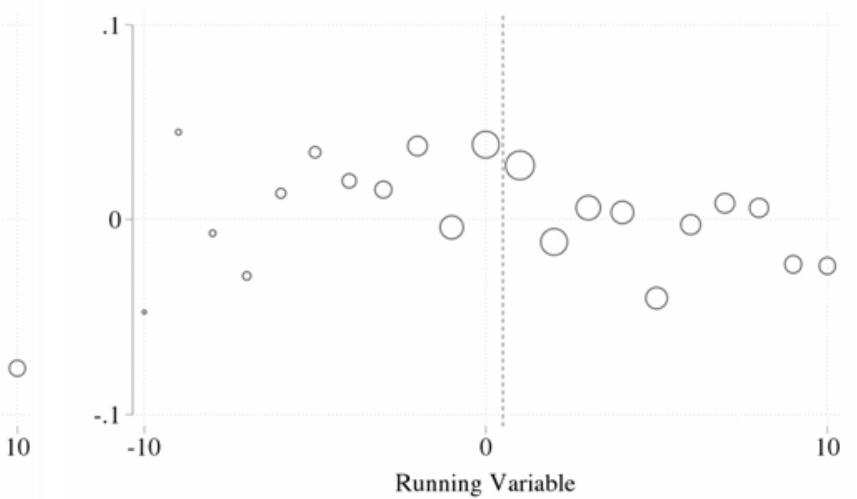

Notes. Each dot represents the mean of the residualized outcome, conditioned on the value of the running variable. The outcomes are residualized by the control variables described in Table 4. Enrollment during the waitlisted term is defined as being enrolled after the add/drop period. The size of the dot reflects the number of observations in each bin. 
Figure A2: Reduced Form Effect of Missing the Waitlist Cutoff on Transfers to Another Two-Year School

(a) Within One Year

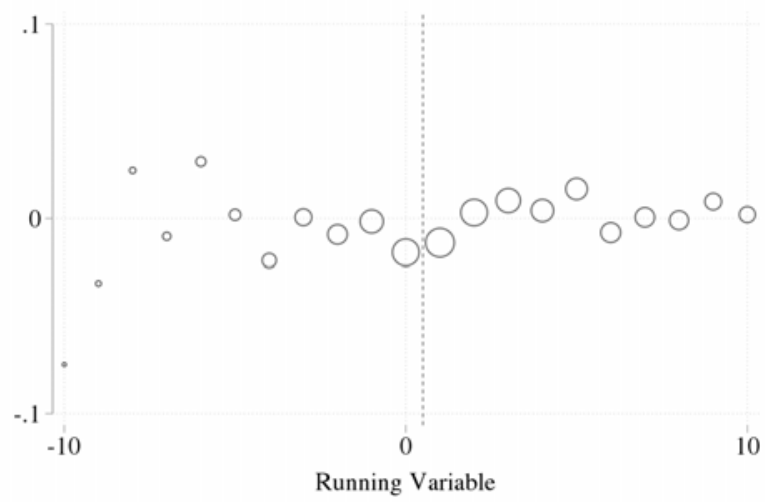

(c) Within Three Years
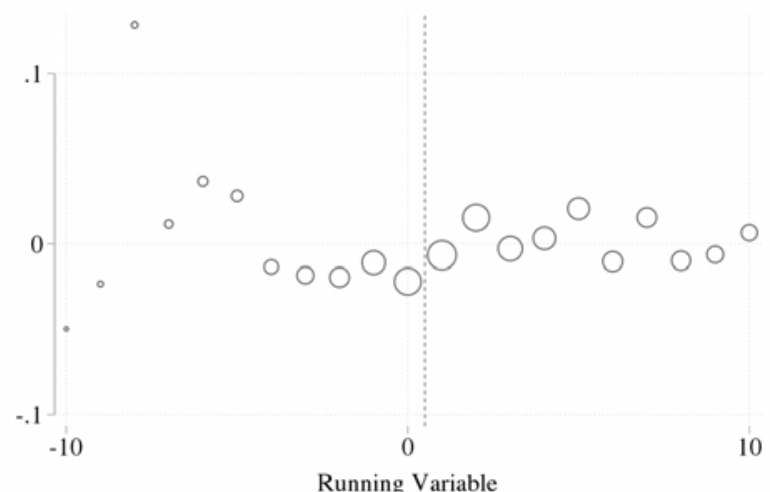

(b) Within Two Years

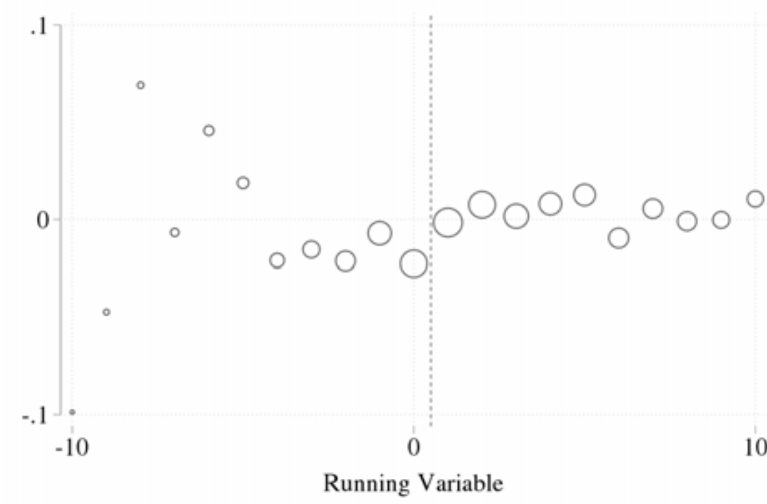

(d) Within Four Years

(e) Within Five Years

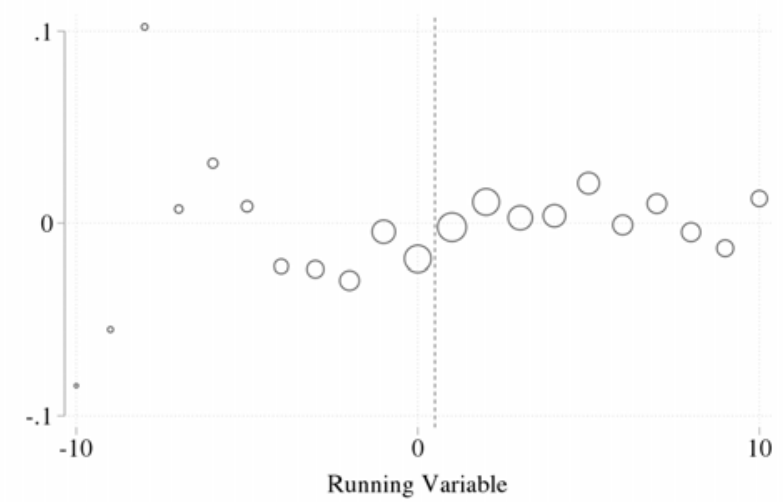

Notes. Each dot represents the mean of the residualized outcome, conditioned on the value of the running variable. The outcomes are residualized by the control variables described in Table 4. The size of the dot reflects the number of observations in each bin. 
Figure A3: Reduced Form Effect of Missing the Waitlist Cutoff on Transfers to a Four-Year School

(a) Within One Year

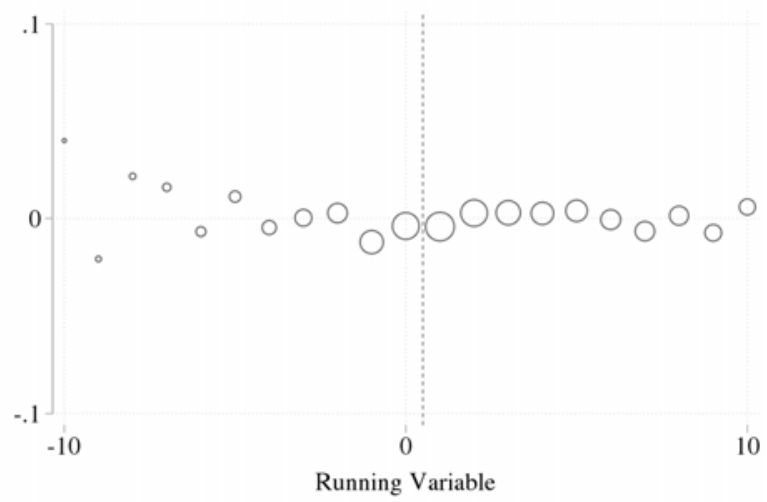

(c) Within Three Years

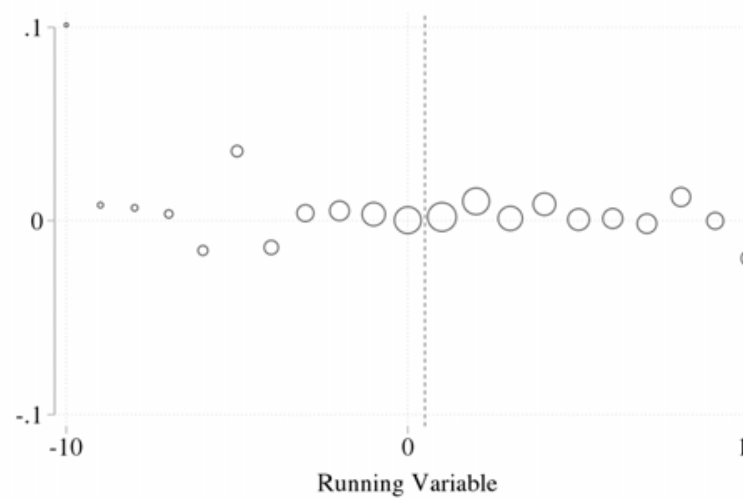

(b) Within Two Years

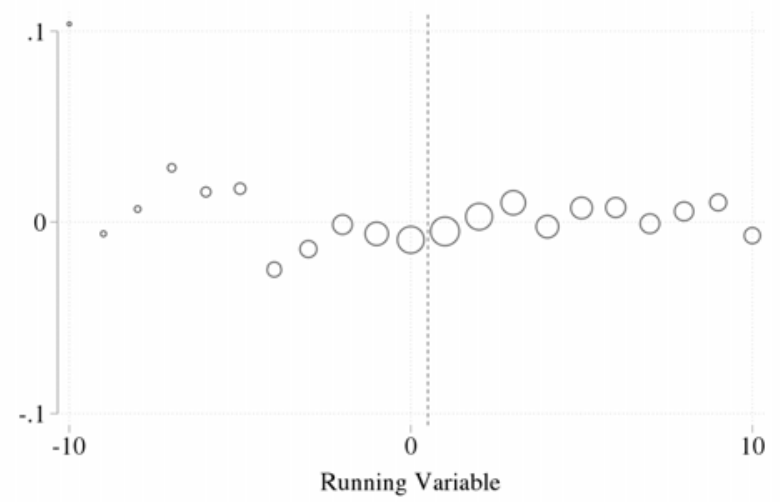

(d) Within Four Years

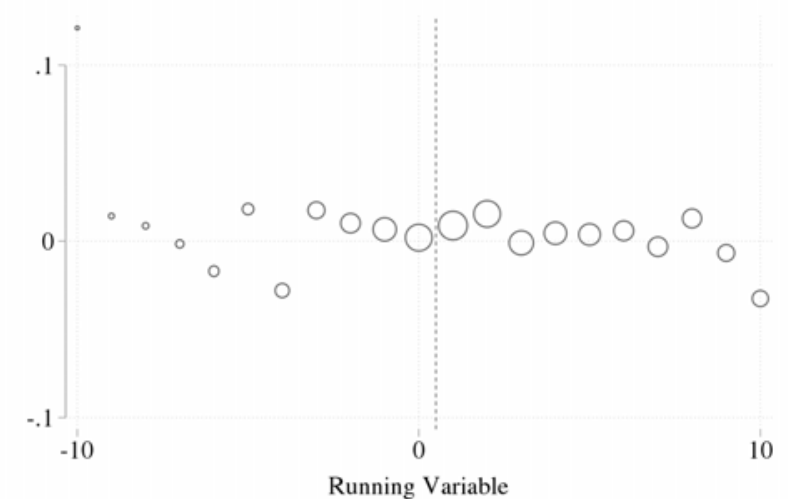

(e) Within Five Years

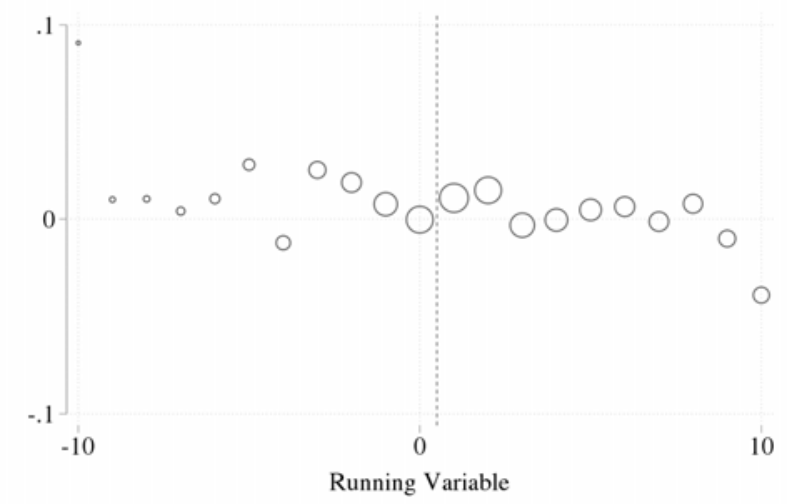

Notes. Each dot represents the mean of the residualized outcome, conditioned on the value of the running variable. The outcomes are residualized by the control variables described in Table 4. The size of the dot reflects the number of observations in each bin. 


\section{B Using Time as the Running Variable}

The main analysis uses a highly discrete running variable, which necessitates local randomization assumptions, but the results are robust to reframing the running variable as a continuous measure defined in terms of registration time. For simplicity, we will now refer to the discrete running variable used in the main analysis as the "position RV" and this new continuous version as the "time RV."

Consider the time of day that each waitlisted student made a registration attempt. The time when the student with a position RV equal to zero signed up for the waitlist creates a cutoff in registration time. Students who signed up to the waitlist before this time could enroll in the section during the registration period (i.e., had a position RV less than or equal to zero), whereas those who signed up after could not (i.e., had a position RV greater than zero). Therefore, the "time RV" is the amount of time, in hours, between when a student signed up for the waitlist and when the student with a position RV of zero registered. In this sense, the analysis compares students who missed the waitlist cutoff to those who just made it, within a window of hours around the cutoff time. ${ }^{27}$

Figure C1 shows the density of the time RV, using the analysis sample without any bandwidth restrictions. Note that there is a large spike at zero. This is a mechanical result due to the definition of the time RV. There is no natural way to set the cutoff; therefore, a position of zero is defined using the position RV from the main analysis. This forces many students to be at or near the cutoff artificially. For this reason, the density fails the manipulation test proposed in McCrary (2008) as well as the more recently proposed test in Cattaneo, Jansson, and Ma (2017). However, there is little chance that the density is a result of systematic manipulation rather than an artifact of the variable definition. The main argument for identification is that, because the time RV, like the position RV, depends on the number of other students who drop, students cannot easily control it.

Figure C2 plots section enrollment rates at the end of the advanced registration period binned by values of the time RV. There is a clearly visible jump in enrollment to the left 
of the cutoff. Table $\mathrm{C} 1$ shows formal estimates of the first stage and confirms that there is a discontinuity in the probability of section enrollment. Students who missed the waitlist cutoff were 82 percentage points more likely to be shut out of their desired section during the advanced registration period, and similarly unlikely to enroll in their desired course during advanced registration. These discontinuities are larger than those in the main analysis, which were 64 and 65 percentage points, respectively.

Table C2 shows the estimates of the LATE on enrollment patterns in the concurrent term. The results are nearly identical to the main analysis. There is a 2.8 percentage point increase in the likelihood of taking no courses in the waitlisted term. The analysis cannot detect a change in the share of students who enrolled part or full-time, though the magnitudes of these are smaller than the drop-out estimate. These results are consistent with the local randomization analysis, which found an increase in stop-out between 2.3 and 2.8 percentage points. 
Figure C1: Density of the Time Running Variable

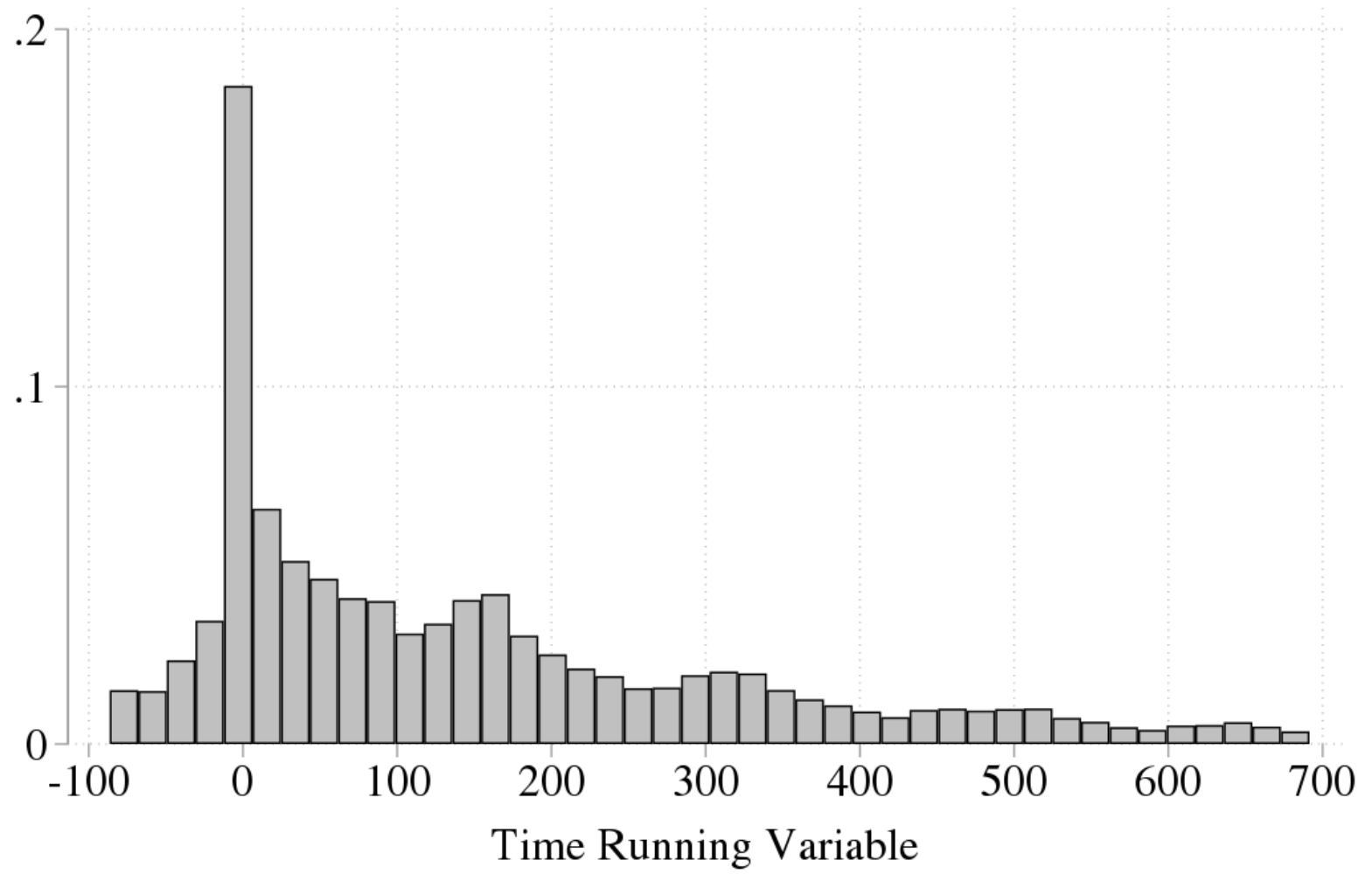

Notes. The time running variable is the amount of time, in hours, between when a student signed up for the waitlist and when the student with a position RV of zero registered. The figure censors time running variables smaller than the 10th and greater than the 90th percentile in order to make it more easily interpretable. 
Figure C2: First Stage Effect of Missing the Waitlist Cutoff on Enrollment in the Waitlisted Section

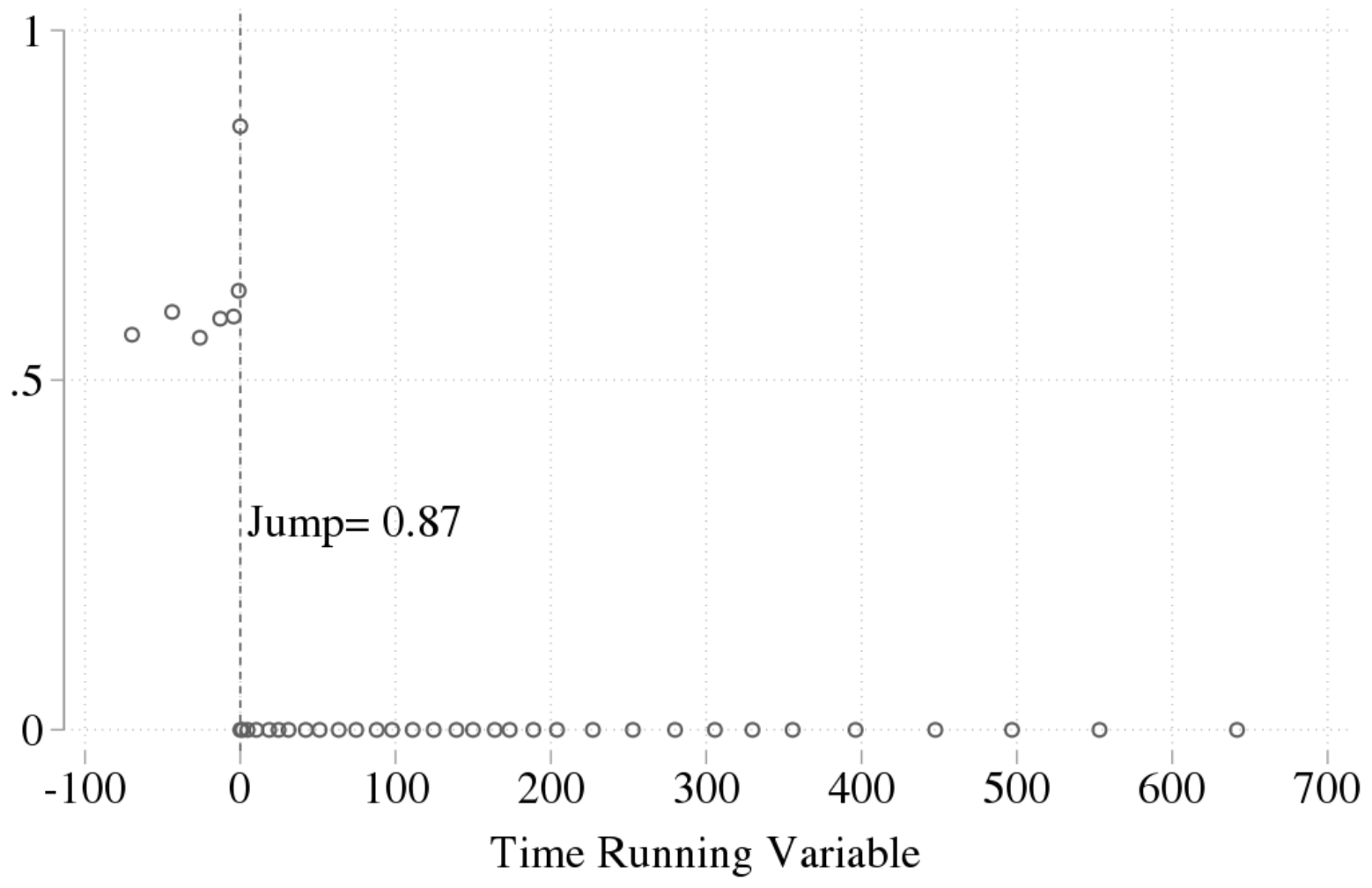

Notes. Each dot represents section enrollment binned in 40 quantiles by the value of the time running variable, where enrollment is equal to one if the student was enrolled in the waitlisted section at the end of the advanced registration period. Section enrollment is equal to zero for students with a time running variable greater than zero by construction. The time running variable is the amount of time, in hours, between when a student signed up for the waitlist and when the student with a position RV of zero registered. The figure censors time running variables smaller than the 10th and greater than the 90th percentile in order to make it more easily interpretable. 
Table C1: First Stage Effect of Missing the Waitlist Cutoff on Enrollment in Waitlisted Section, Using Time Running Variable

Enrolled in Section Enrolled in Section

\begin{tabular}{|c|c|c|}
\hline Missed WL Cutoff & $\begin{array}{c}-0.818^{* * *} \\
(0.009)\end{array}$ & $\begin{array}{c}-0.817^{* * *} \\
(0.009)\end{array}$ \\
\hline $\begin{array}{l}\text { Observations }\left(N_{l} / N_{r}\right) \\
\text { CCT BW } \\
\text { Controls }\end{array}$ & $\begin{array}{l}2404 / 1285 \\
10.797 \\
\text { N }\end{array}$ & $\begin{array}{c}2403 / 1282 \\
10.748 \\
Y\end{array}$ \\
\hline \multicolumn{3}{|c|}{$\begin{array}{l}\text { Notes: Results are from a local linear regression using time as the continuous } \\
\text { running variable. The dependent variable is enrollment in the waitlisted section, } \\
\text { where enrollment is equal to one if the student was enrolled at the end of the } \\
\text { advanced registration period. The bandwidth is calculated according to the } \\
\text { CCT optimal bandwidth selection procedure. The first column does not include } \\
\text { controls, whereas the second column controls for the covariates listed in Table } \\
\text { 4. Standard errors are robust to heteroskedasticity. ( }{ }^{*} p<0.1,{ }^{* *} p<0.05,{ }^{* * *} \\
p<0.01 \text { ) }\end{array}$} \\
\hline
\end{tabular}


Table C2: Effect of Missing the Waitlist Cutoff on Course Load, Using Time Running Variable

\begin{tabular}{lccc} 
& \multicolumn{3}{c}{ \# Courses Enrolled in Concurrent Term } \\
\hline & Zero & One or Two & Three or More \\
& $(1)$ & $(2)$ & $(3)$ \\
\hline 2SLS & $0.028^{*}$ & -0.010 & -0.017 \\
& $(0.016)$ & $(0.023)$ & $(0.023)$ \\
Reduced Form & $0.022^{*}$ & -0.008 & -0.013 \\
& $(0.013)$ & $(0.018)$ & $(0.018)$ \\
Observations $\left(N_{l} / N_{r}\right)$ & $3,057 / 2,582$ & $3,054 / 2,574$ & $3,175 / 2,831$ \\
CCT BW & 29.877 & 29.684 & 35.336 \\
\hline
\end{tabular}

Notes: Results are from a local linear regression using time as the continuous running variable. The outcome is an indicator for whether the student took no courses in the concurrent term in Column (1), took one or two courses in Column (2), or took three or more courses in Column (3). A course is counted if the student is enrolled after the add/drop date. The bandwidth is calculated according to the CCT optimal bandwidth selection procedure. The first column does not include controls, whereas the second column controls for the covariates listed in Table 4. Standard errors are robust to heteroskedasticity. $\left(* p<0.1,{ }^{* *} p<0.05,{ }^{* * *}\right.$ $p<0.01)$ 